\title{
Mechanically stable monolithic porous boron nitride with high volumetric adsorption capacity
}

Tian Tian, Jingwei Hou, Humera Ansari, Ying Xiong, Anouk L'Hermitte, David Danaci, Ronny Pini, and Camille Petit*

Dr. T. Tian, Dr. Y. Xiong, A. L’Hermitte, Dr. D. Danaci, Dr. C. Petit

Barrer Centre, Department of Chemical Engineering

Imperial College London, South Kensington Campus

London SW7 2AZ, UK

E-mail: camille.petit@imperial.ac.uk

Dr. J. Hou

School of Chemical Engineering

University of Queensland

QLD 4072, Australia

H. Ansari, Dr. R. Pini

Department of Chemical Engineering

Imperial College London, South Kensington Campus

London SW7 2AZ, UK

\author{
A. L'Hermitte \\ Department of Materials \\ Imperial College London, South Kensington Campus \\ London SW7 2AZ, UK
}

Keywords: porous boron nitride, monolith, density, mechanical strength, gas adsorption, formation mechanism

The development of adsorbents into structured and robust forms remains a challenge for emerging porous materials. In the context of porous boron nitride $(\mathrm{BN})$, studies point to a tradeoff between mechanical stability, porosity, density, and adsorption kinetics. Approaches towards shaping and densification of porous BN have been mostly empirical since a detailed understanding of its formation mechanism, and how it impacts mechanical strength and porosity, is lacking. Here, we demonstrate a synthesis method that can directly produce a mechanically robust monolithic porous $\mathrm{BN}(\mathrm{mp} B N)$ from an easily scalable polymeric precursor, which results in the highest volumetric surface area among porous $\mathrm{BN}$ samples to date. ${ }_{\mathrm{mpN}} \mathrm{BN}$ exhibits a high bulk density, 50\% higher than BN powders and over ten times higher than the structured BN aerogels, while maintaining fast sorption kinetics. ${ }_{\mathrm{mpN}} \mathrm{BN}$ presents good mechanical strength, 
with hardness of $66.4 \pm 4.5 \mathrm{MPa}$, i.e. one to two orders of magnitude higher than structured aerogels. We propose a ${ }_{m p} B N$ formation mechanism which reveals that the crosslinked intermediates are responsible for the high mechanical strength of the final material. Our approach produces a form of BN that addresses the limitations of other adsorbents, and facilitate their application in gas separation and storage technologies.

\section{Introduction}

Owing to their high surface area, large porosity and rich surface functionalities, porous materials (e.g. zeolites, activated carbon, and metal-organic frameworks) can be used in a range of applications from catalysis to gas separation, and storage. ${ }^{[1-3]}$ Processing these materials from powders to robust densified structures (e.g. pellets, beads, and monoliths) represents a necessary step towards their industrial deployment. Indeed, powders suffer from limited mass transfer and poor mechanical strength and they are difficult to handle at scale. ${ }^{[4,5]}$ The large amount of interparticle space in powders also causes low bulk density and low volumetric adsorption/storage capacity, ${ }^{[6,7]}$ which in turn, leads to an increased footprint. ${ }^{[8,9]}$

Shaping and densifying powders into mechanically robust structures can be done as follows: (i) mechanical compaction, (ii) application of binders, or (iii) growth on monolithic supports. ${ }^{[7]}$ These approaches usually result in decreased performance due to pore collapse from highpressure, pore blockage from binders, or 'dead' volume from the support. Recently, Tian et al. developed a methodology towards the densification of metal organic frameworks via a sol-gel method without using high-pressure compaction or binders, providing scope for the development of monolithic porous materials. ${ }^{[9]}$ However, the advances of producing other robust porous materials is still lacking, particularly for ceramics. ${ }^{[10]}$

Amorphous boron nitride $(\mathrm{BN})$ represents a relatively new addition to the porous materials family, ${ }^{[11-16]}$ with recent studies demonstrating its use in molecular separation, ${ }^{[13,17-22]}$ catalysis, ${ }^{[23]}$ and drug delivery. ${ }^{[24]}$ Like other porous materials, identifying a way to shape and 
densify $\mathrm{BN}$ without compromising the porosity is needed. We note increasing focus towards producing structured $\mathrm{BN}$ in the recent literature. For example, $\mathrm{BN}$ aerogel, the most common form of structured $\mathrm{BN}$, has been synthesized using various methods such as direct chemical reaction, ${ }^{[25,26]}$ carbonaceous template assisted method, ${ }^{[27-29]}$ or molecular substitution. ${ }^{[30]}$ Yet, all structured BN aerogels exhibit low density and mechanical strength, preventing their upscaling for practical adsorption applications. Sintering, another important method to synthesize structured $\mathrm{BN}$, usually leads to a low surface area, albeit with high mechanical strength. ${ }^{[31]}$ Overall, these studies lead to two main observations: (i) a tradeoff persists between mechanical stability, porosity, density and adsorption kinetics; (ii) approaches towards shaping and densification of porous BN have been mostly empirical since a detailed understanding of porous $\mathrm{BN}$ formation mechanism and how it impacts mechanical strength and porosity is lacking. We hypothesize that higher bonding densities within BN will allow good resistance to deformation and loading. Hence, monitoring the formation mechanism of porous $\mathrm{BN}$ and linking it to mechanical strength will be important towards developing robust densified porous BN structures.

Herein, we present a method to synthesize a monolithic porous $\mathrm{BN}$, named $\mathrm{mp} \mathrm{BN}$, that exhibits high surface area, mechanical strength and enhanced volumetric adsorption capacity compared to powder $\mathrm{BN}$. ${ }_{\mathrm{mp}} \mathrm{BN}$ also shows enhanced hydrolytic stability compared to $\mathrm{BN}$ powders, owing to a reduced oxygen content. Our method does not involve any compaction, binding or supporting step but instead relies on the use of a mechanically stable polymer precursor, a melamine-formaldehyde (MF) resin. $\mathrm{MF}$ resins have been well-developed at industry scale, making the current synthesis method suitable for upscaling. Through in-depth XPS and FTIR analyzes, we determine the formation mechanism of ${ }_{\mathrm{mp}} \mathrm{BN}$ starting from this polymer and how it influences the resulting mechanical stability.

\section{Results and Discussion}

\subsection{Synthesis of monolithic porous $B N(\mathrm{mp} B N)$}


We used a macroporous melamine-formaldehyde (MF) resin as the precursor to produce monolithic porous BN, mpN (Scheme 1). To synthezise the resin, we employed dicyandiamide (DCD) as a foaming agent, ${ }^{[32]}$ and boric acid as the curing agent. The pore density in the MF resin was controlled by the DCD content and appears to impact the final morphology of the porous BN (Figure 1). Indeed, on the one hand, a low DCD content results in a non- or poorly porous MF resin, as indicated by the low 'bubbles' density observed on the microscope images (Figure S1). We attribute this behavior to the fact that gases generated during pyrolysis could not easily 'escape' through the tight resin, thus leading to pressure build-up and eventually structure collapse (Figure 1a, 1b). On the other hand, a high DCD content formed a highly porous resin (Figure S1). We speculate that the low crosslink density (i.e. high porosity) of the resin meant that it was too fragile to withstand the chemical decomposition and gas release during pyrolysis, leading to the formation of powder (Figures 1e). Overall, we have found that a DCD/melamine weight ratio of 0.72 resulted in a precursor with moderate pore density and high mechanical strength. In this case, the pores act as channels for the porogen to escape while the good crosslink density prevents the collapse of the macrostructure upon pyrolysis. As a result, we obtain a monolithic $\mathrm{BN}$ sample (Figure 1c, 1d).
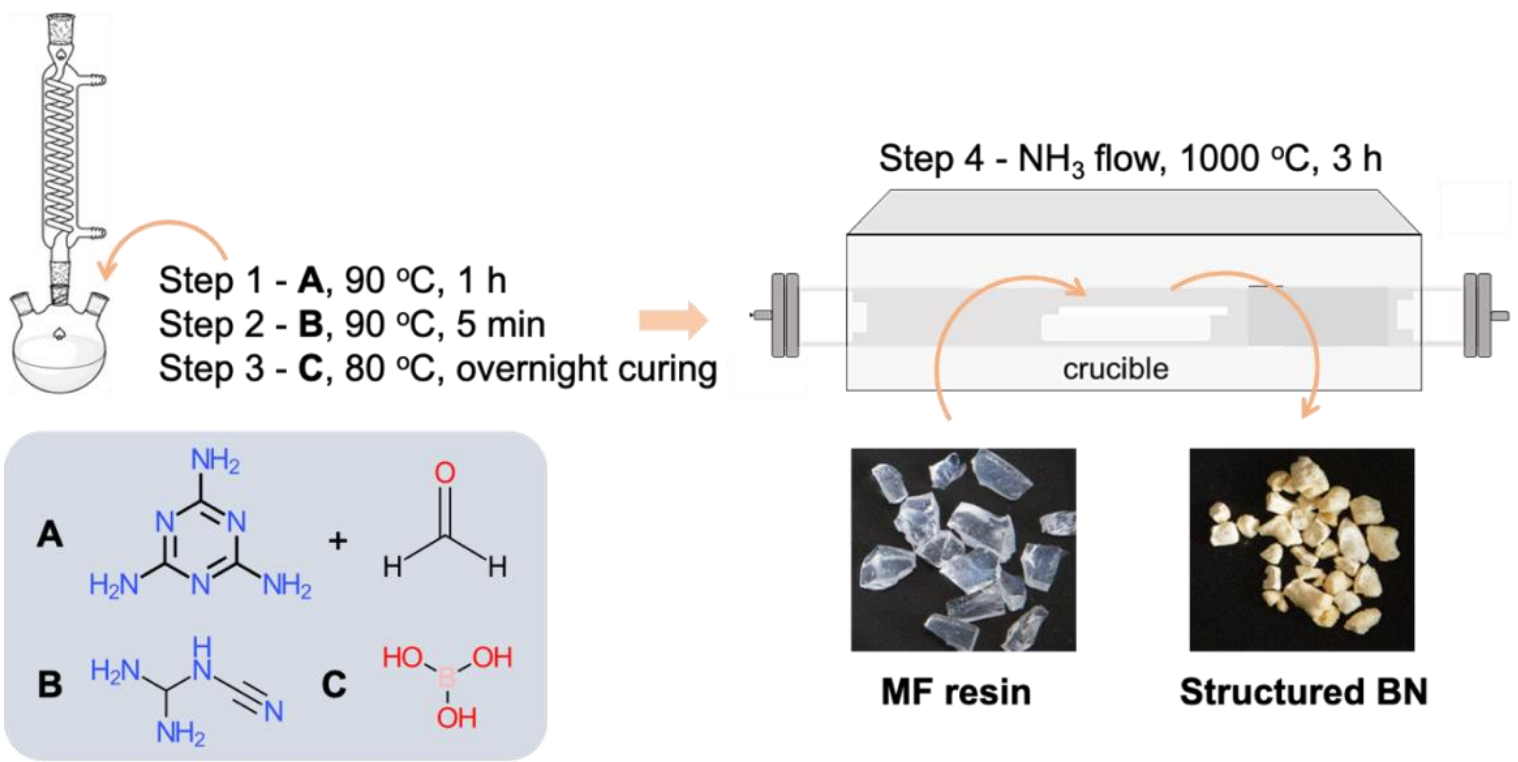

Scheme 1. Schematic representation of monolithic porous $B N\left({ }_{m p} B N\right)$ synthesis via the formation of a melamine-formaldehyde resin (MF resin). A = Melamine + Formaldehyde; $\mathrm{B}=$ Dicyandiamide, $\mathrm{C}=$ Boric acid. 

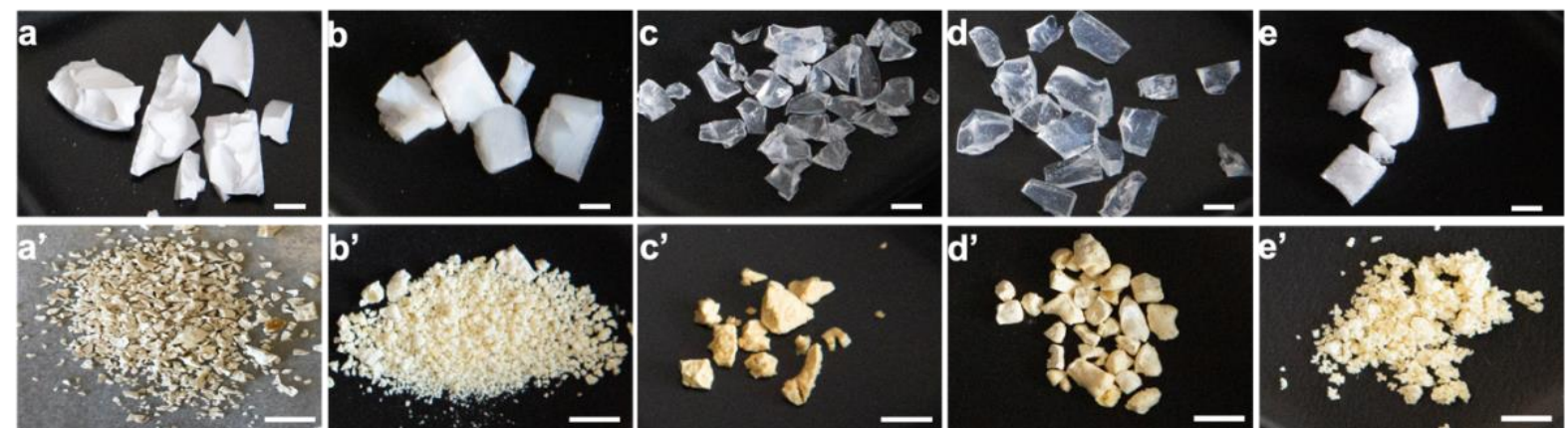

Figure 1. Optical images of the melamine-formaldehyde (MF) resin with different amounts of foaming agent, DCD (a-e), and the derived porous BN samples (a'-e'). DCD/melamine weight ratio of (a) and (a') 0; (b) and (b') 0.24; (c) and (c') 0.48; (d) and (d') 0.72; (e) and (e') 0.96. Scale bar $=1 \mathrm{~cm}$.

Based on the observations above, we then focused our attention on the BN samples obtained using a $0.72 \mathrm{DCD} /$ melamine weight ratio (Figures 1d and S2). We explored the effects of reaction atmosphere, reaction temperature and duration on the pyrolysis product to identify the optimal pyrolysis conditions. Looking first at the reaction atmosphere, we note significant differences between the products obtained under either $\mathrm{NH}_{3}$ or $\mathrm{N}_{2}$, starting from the color: yellowish vs black, respectively. As shown in Figure $\mathrm{S} 3$, the sample obtained under $\mathrm{NH}_{3}$ exhibits a higher BET specific surface area than that obtained under $\mathrm{N}_{2}\left(1513 \mathrm{~m}^{2} \mathrm{~g}^{-1} \mathrm{vs} 216 \mathrm{~m}^{2}\right.$ $\left.\mathrm{g}^{-1}\right)$. These differences result from the amount of active $\mathrm{N}$-containing gases $\left(\right.$ e.g. $\left.\mathrm{NH}_{3}\right)$ during the synthesis. Under $\mathrm{N}_{2}$, the reactive $\mathrm{N}$ source comes principally from the resin and is insufficient for complete reaction with boric acid. Therefore, carbonization is predominant resulting in a black sample with a low surface area. In contrast, the synthesis under $\mathrm{NH}_{3}$ provides an excess of reactive $\mathrm{N}$ over a wide range of temperature, which is known to enhance the surface area of porous BN. ${ }^{[20]}$ Consequently, $\mathrm{NH}_{3}$ was selected as the reaction atmosphere for further tests.

Next, we investigated the effects of the reaction temperature and the duration of the isothermal step. Keeping the duration at 3 h, the BET specific surface area increased from 1349 $\mathrm{m}^{2} \mathrm{~g}^{-1}$ at $800{ }^{\circ} \mathrm{C}$ to $1513 \mathrm{~m}^{2} \mathrm{~g}^{-1}$ at $1000{ }^{\circ} \mathrm{C}$ (Figure 2a). Further increasing the reaction temperature to $1200{ }^{\circ} \mathrm{C}$ resulted in a decreased BET area $\left(1397 \mathrm{~m}^{2} \mathrm{~g}^{-1}\right)$, possibly due to a partial 
crystallization of BN. ${ }^{[13,30]}$ Furthermore, extending the duration of the isothermal step up to $3 \mathrm{~h}$ at $1000{ }^{\circ} \mathrm{C}$ enhanced the porosity (Figure $2 \mathrm{~b}$ ). Beyond $3 \mathrm{~h}$, the surface area reached a plateau, pointing towards a completion of the reactions leading to the gases release and porosity formation. To summarize, pyrolizing the MF resin in $\mathrm{NH}_{3}$ atmosphere at $1000{ }^{\circ} \mathrm{C}$ for $3 \mathrm{~h}$ appeared the most effective method in obtaining ${ }_{\mathrm{mp}} \mathrm{BN}$ and was used in the current work.

a

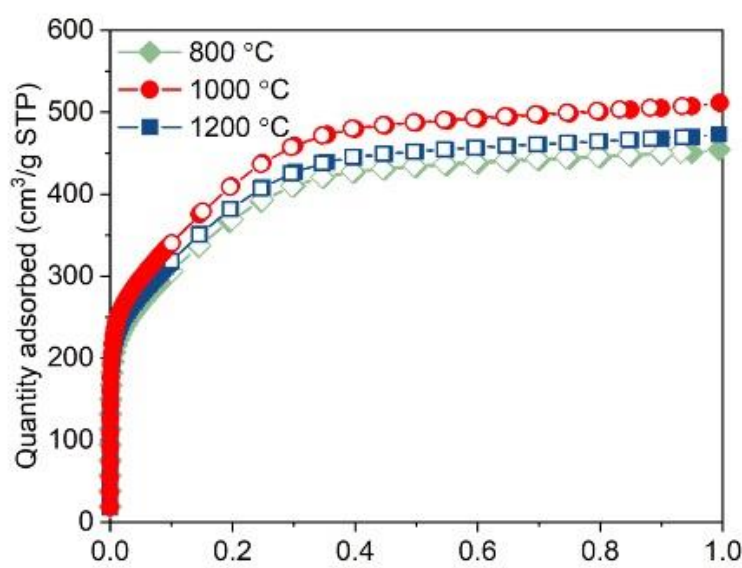

b

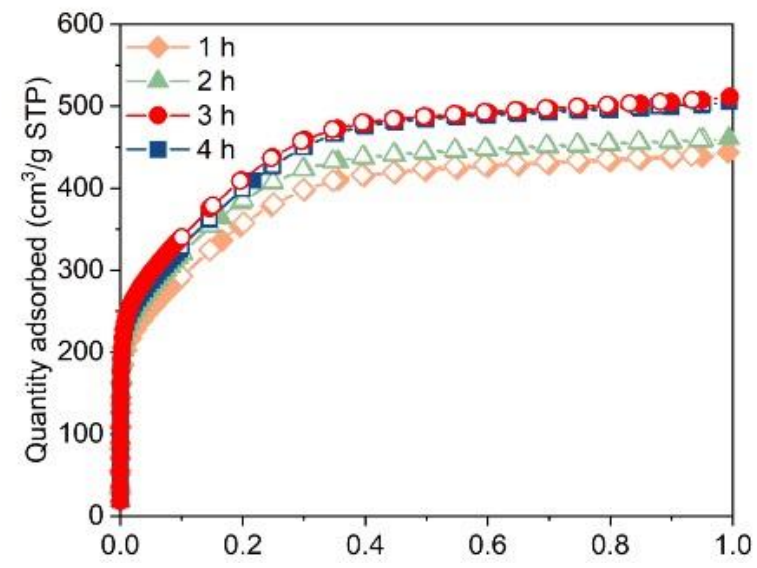

Figure 2. Analysis of the pyrolysis conditions on the porosity of $B N . N_{2}$ sorption isotherms of monolithic porous $\mathrm{mp}_{\mathrm{BN}}$ at $77 \mathrm{~K}$. a) pyrolyzed for $3 \mathrm{~h}$ at different temperatures; b) pyrolyzed at $1000{ }^{\circ} \mathrm{C}$ for increasing durations.

\subsection{Characterization of monolithic porous $B N(\mathrm{mp} B N)$}

We now analyze in more detail the features of ${ }_{\mathrm{mp}} \mathrm{BN}$ obtained using the optimal conditions determined above. Figure 3a shows the XRD pattern of the sample. The two broad peaks corresponding to (002) and (100) planes together with the absence of other reflections point to the presence of turbostratic/amorphous BN. ${ }^{[30]}$ The two main characteristic IR bands of $\mathrm{BN}$ at $\sim 1360 \mathrm{~cm}^{-1}$ (in-plane BN stretching) and $\sim 810 \mathrm{~cm}^{-1}$ (out-of-plane B-N-B bending) are detected (Figure 3b), confirming the chemical composition of ${ }_{m p B N}{ }^{[20]}$ We attribute the additional small band at $\sim 1100 \mathrm{~cm}^{-1}$ to B-O bending mode. ${ }^{[23]}$ The presence of oxygen is further confirmed by XPS analyzes, with a quantity of 3 at $\%$ (Figure $3 \mathrm{~d}$ ). The lower oxygen content of $\mathrm{mp} B \mathrm{~N}$ compared to powder BN (3 at\% vs 9 at\%) leads to a significant improvement of hydrolytic stability, an important feature for industrial application, as shown in Figures S4 and S5. ${ }^{[33]}$ SEM 
image of ${ }_{\mathrm{mp}} \mathrm{BN}$ (Figure $3 \mathrm{c}$ ) reveals a continuous solid phase with slender cracks. The compact solid phase presents a relatively flat surface similar to other highly dense monolithic porous materials. ${ }^{[8,9]}$ The morphology is different from that of powders or aerogels, which contain a large amount of interparticle space. ${ }^{[20,29]}$ The slender cracks with macropores are distributed within the continuous flat surface and may result from the pores in the resin precursor. The pores propagated and enlarged under the stress generated during the synthesis, forming these gully-like cracks.
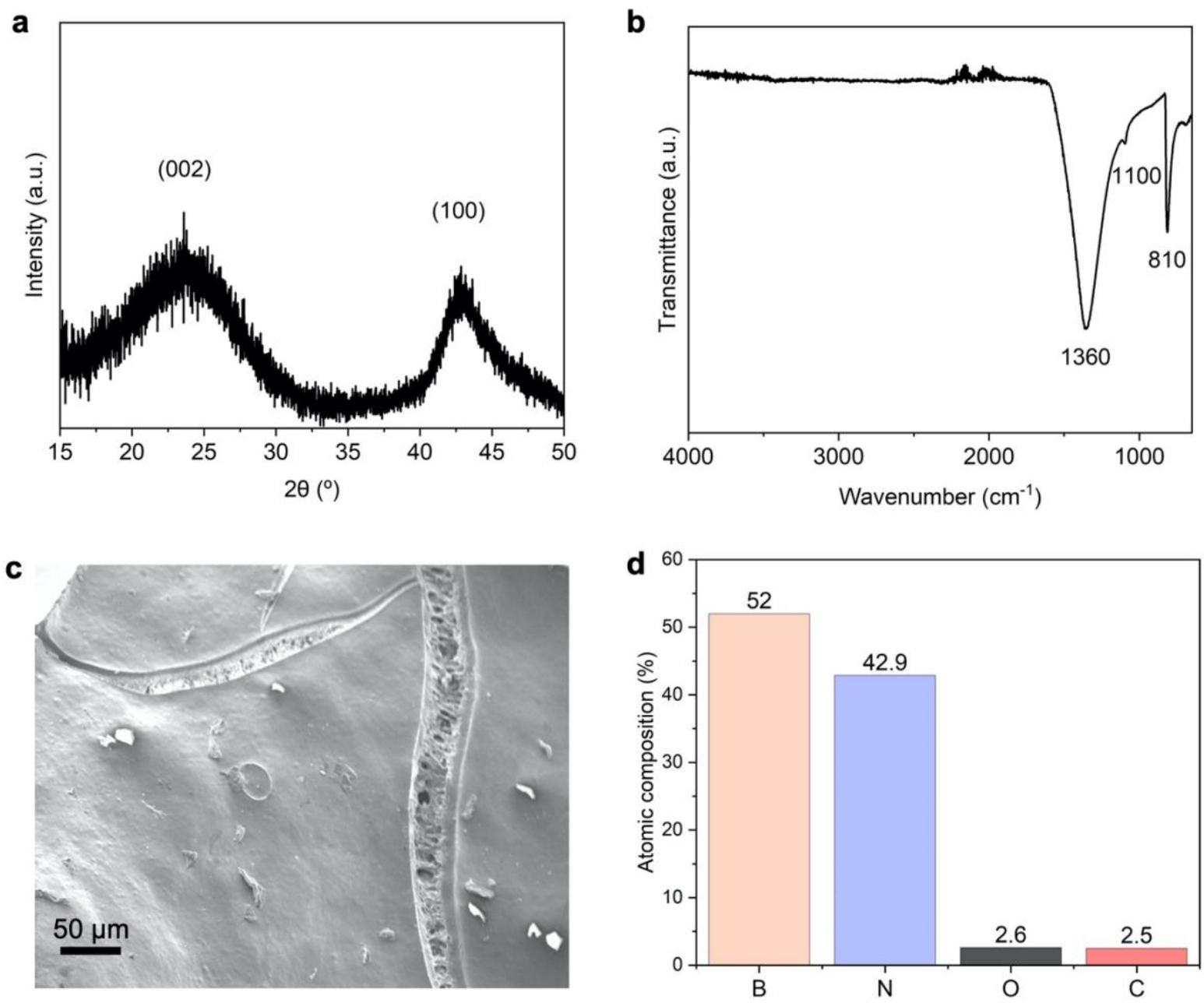

Figure 3. Structure, morphology and surface composition of monolithic porous BN, ${ }_{\mathrm{mp}} \mathrm{BN}$. (a) XRD patterns; (b) FTIR spectrum; (c) SEM image; (d) XPS relative atomic percentages.

\subsection{Textural and gas adsorption properties of monolithic porous $B N(m p B N)$ vs powder} BN 
We evaluated the porosity of ${ }_{\mathrm{mp}} \mathrm{BN}$ using the $\mathrm{N}_{2}$ adsorption isotherms at $77 \mathrm{~K}$ and compared it with a highly porous BN powder recently reported by our group (Table 1, Figure S6). ${ }^{[20,23]}$ ${ }_{\mathrm{mp}} \mathrm{BN}$ possesses a similar specific surface area to powder BN. However, different to powder BN which exhibits type IV isotherms, ${ }_{m} B N$ exhibits a type $\mathrm{I}(\mathrm{b})$ isotherm, typical for materials with both micropores and narrow mesopores. ${ }^{[34]}$ The pore size distribution in Figure S7 shows that the majority of the pores in ${ }_{\mathrm{mp}} \mathrm{BN}$ are $<2.5 \mathrm{~nm}$. Furthermore, $\mathrm{N}_{2}$ sorption in $\mathrm{mp}_{\mathrm{BN}}$ plateaus for $\mathrm{P} / \mathrm{P}_{0}>0.5$. On the contrary, $\mathrm{N}_{2}$ adsorption in powder $\mathrm{BN}$ increases towards high $\mathrm{P} / \mathrm{P}_{0}$ values due to $\mathrm{N}_{2}$ condensation. This is due to the compact nature of ${ }_{\mathrm{mp}} \mathrm{BN}$, which results in minimal interparticle porosity.

To quantify the compact nature of ${ }_{\mathrm{mp}} \mathrm{BN}$, we measured its bulk density using mercury porosimetry, a well-established technique that has been used to measure the bulk density of other porous materials. ${ }^{[35]}$ Mercury is a non-wetting liquid that does not intrude small pores at ambient pressure, which facilitates the measurement of bulk volume and thus the density (Section S3.2). Table 1 shows the bulk density of ${ }_{\mathrm{mpN}} \mathrm{BN}$ was $0.31 \mathrm{~g} \mathrm{~cm}^{-3}$, nearly $50 \%$ higher than that of the bulk powder, which leads to a significantly higher volumetric BET area, achieving $473 \mathrm{~m}^{2} \mathrm{~cm}^{-3}$ (vs $315 \mathrm{~m}^{2} \mathrm{~cm}^{-3}$ for powder $\mathrm{BN}$ ). We note that structured $\mathrm{BN}$ aerogels usually exhibit bulk densities of $0.01-0.02 \mathrm{~g} \mathrm{~cm}^{-3},{ }^{[25,26,36-40]}$ more than one order of magnitude lower than that of ${ }_{\mathrm{mp}} \mathrm{BN}$, ultimately leading to a low volumetric BET area (i.e. $0.1-14 \mathrm{~cm}^{2} \mathrm{~cm}^{-}$ ${ }^{3}$ ). On the other hand, sintered structured BN typically shows high density but a low BET area $\left(<450 \mathrm{~m}^{2} \mathrm{~g}^{-1}\right),{ }^{[31]}$ which results in a moderate volumetric BET area similar to the powder BN. ${ }_{\mathrm{mp}} \mathrm{BN}$ therefore exhibits the highest volumetric BET area for a BN sample published to date.

Table 1. Comparison of gravimetric and volumetric properties of monolithic porous $\mathrm{BN}(\mathrm{mp} B N)$ and powder BN. BET area $\left(\mathrm{S}_{\mathrm{BET}}(\mathrm{g})\right)$, total pore volume $\left(\mathrm{V}_{\text {tot }}\right)$, micropore volume $\left(\mathrm{V}_{\text {micro }}\right)$ obtained from $\mathrm{N}_{2}$ sorption isotherms at $77 \mathrm{~K}$ and bulk density $(\rho)$ and volumetric BET area (S $\mathrm{SET}_{\mathrm{BET}}(\mathrm{vol})$ ) derived from mercury porosimetry.

\begin{tabular}{cccccc}
\hline & $\begin{array}{c}\mathrm{S}_{\text {BET }} \text { (mass) } \\
{\left[\mathrm{m}^{2} \mathrm{~g}^{-1}\right]}\end{array}$ & $\begin{array}{c}\mathrm{V}_{\text {tot }} \\
{\left[\mathrm{cm}^{3} \mathrm{~g}^{-1}\right]}\end{array}$ & $\begin{array}{c}\mathrm{V}_{\text {micro }} \\
{\left[\mathrm{cm}^{3} \mathrm{~g}^{-1}\right]}\end{array}$ & $\begin{array}{c}\rho \\
{\left[\mathrm{g} \mathrm{cm}^{-3}\right]}\end{array}$ & $\begin{array}{c}\mathrm{S}_{\text {BET }}(\mathrm{vol}) \\
{\left[\mathrm{m}^{2} \mathrm{~cm}^{-3}\right]}\end{array}$ \\
\hline Monolithic ${ }_{\mathrm{mp}} \mathrm{BN}$ & 1523 & 0.79 & 0.56 & 0.31 & 473
\end{tabular}


Volumetric methane storage capacity can be attractive for on board applications, where space for fuel is always a constraint. In these cases, the volumetric methane uptake is to be considered. Considering the volumetric properties of $\mathrm{mpBN}_{\mathrm{N}}$, we performed $\mathrm{CH}_{4}$ adsorption isotherms at 298 $\mathrm{K}$ up to 70 bar. Figure 4a shows that the absolute gravimetric uptake of ${ }_{\mathrm{mp}} \mathrm{BN}$ is comparable to that of powder BN, owing to the similar surface area and micropore volume. Remarkably, $\mathrm{mp} B \mathrm{~N}$ shows a significant enhancement when considering the absolute volumetric adsorption capacity (59 vs $42(\mathrm{STP}) \mathrm{cm}^{3} \mathrm{~cm}^{-3}$ at 70 bar) as a result of the higher bulk density of $\mathrm{mpBN}$ (Figure $4 \mathrm{~b}$ ).

A higher material density often compromises adsorption kinetics due to the mass transfer limitation. To explore the adsorption kinetics of ${ }_{\mathrm{mp}} \mathrm{BN}$, we measured the adsorption equilibration time of $\mathrm{N}_{2}$ adsorption at an extremely low pressure $\left(2.2 \times 10^{-6}\right.$ bar $)$ at $77 \mathrm{~K}$ and compared the results to those obtained for the powder sample (Figure S9). At very low pressures, differences in kinetics between the two materials are likely to be the most visible, hence the selection of $2.2 \times 10^{-6}$ bar for the measurement. Both samples show very fast adsorption kinetics, reaching equilibrium within 60s. The small difference was mainly attributed to the lower macroporosity in ${ }_{\mathrm{mp}} \mathrm{BN}$, which results in a slightly lower diffusivity. 

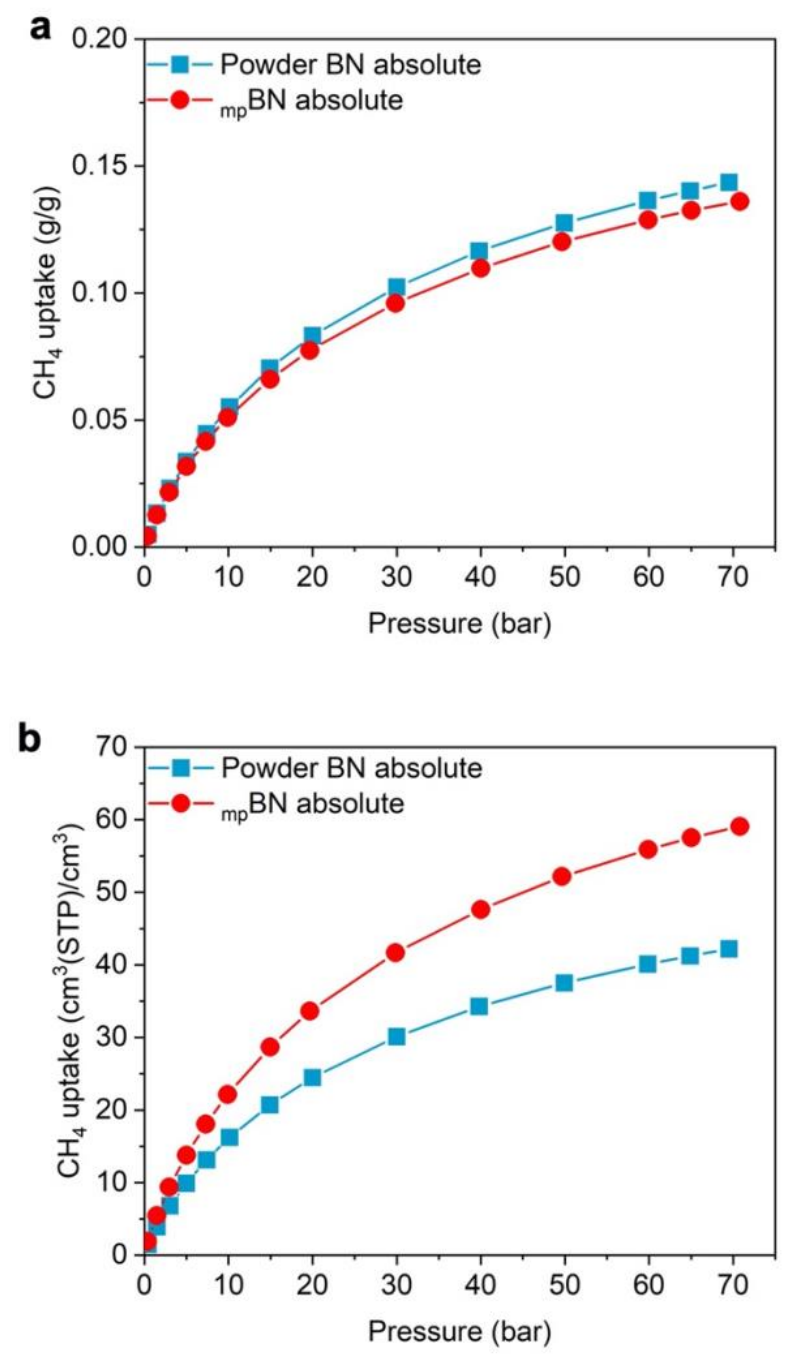

Figure 4. Comparison of absolute methane uptake at $298 \mathrm{~K}$ between powder BN (blue squares) and $\mathrm{mp} \mathrm{BN}$ (red circles).

\subsection{Mechanical stability of monolithic porous $\mathrm{BN}(\mathrm{mp} B \mathrm{~N})$}

Mechanical stability of adsorbents is an important property in practical applications as materials are always exposed to mechanical stress such as operational vibration and compression, i.e. weight of the packed adsorbent. As a preliminary and quick visual test of the mechanical

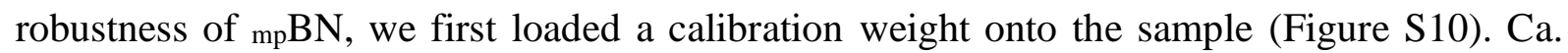
$0.005 \mathrm{~g}$ of $\mathrm{mp} \mathrm{BN}$ maintained its integral bulk structure under a $200 \mathrm{~g}$ calibration weight, pointing to an apparent robustness. We then evaluated quantitatively the hardness of the sample using microindentation. Our results show the hardness of ${ }_{\mathrm{mp} B N}$ is $66.4 \pm 4.5 \mathrm{MPa}$, which is comparable to dense binder-free graphene oxide pellets ${ }^{[41]}$ and macroporous nickel foam. ${ }^{[42]}$ 
Remarkably, the hardness is 1-2 orders of magnitude higher than that reported for $\mathrm{BN}$ aerogels, ${ }^{[43,44]}$ suggesting a much higher resistance to plastic deformation, mainly attributed to the higher density.

\subsection{Formation mechanism of monolithic porous $\mathrm{BN}(\mathrm{mpBN})$}

Finally, we aimed to understand the formation mechanism of ${ }_{\mathrm{mp}} \mathrm{BN}$ and its impact on the mechanical stability of the material by analyzing the structural evolution from MF resin to $\mathrm{mp} B N$. To do so, we collected samples obtained from the pyrolysis of MF resin under $\mathrm{NH}_{3}$ at different temperatures: $200,300,400,600,800$ and $1000{ }^{\circ} \mathrm{C}$. We then analyzed the structural and chemical properties of these intermediates. Figure 5 presents the optical images of the intermediates and highlights significant changes in aspect as the sample subsequently turned brown $\left(300{ }^{\circ} \mathrm{C}\right)$, black $\left(400\right.$ and $\left.600{ }^{\circ} \mathrm{C}\right)$, brown $\left(800{ }^{\circ} \mathrm{C}\right)$ and yellow $\left(1000{ }^{\circ} \mathrm{C}\right)$.

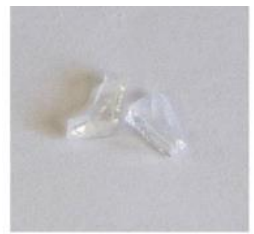

$200{ }^{\circ} \mathrm{C}$

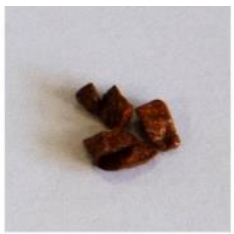

$300{ }^{\circ} \mathrm{C}$

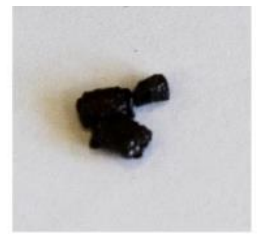

$400{ }^{\circ} \mathrm{C}$

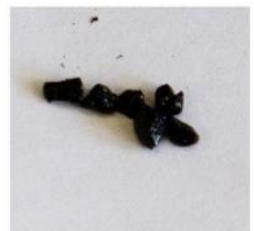

$600{ }^{\circ} \mathrm{C}$

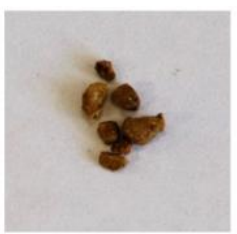

$800^{\circ} \mathrm{C}$

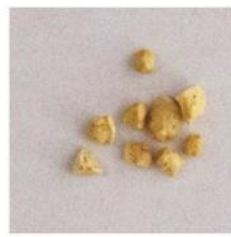

$1000^{\circ} \mathrm{C}$

Figure 5. Optical images of melamine-formaldehyde resin (MF resin) heated at increasing temperatures under $\mathrm{NH}_{3}$ atmosphere.

We used XPS to identify the chemical structure of the intermediates. The core level spectra of B1s, N1s and O1s are presented in Figure 6a-c. The intermediate collected at $200{ }^{\circ} \mathrm{C}$ shows the typical melamine resin spectrum, namely two peaks located at $339.4 \mathrm{eV}$ (pyrrodic $\mathrm{N}$ ) and $398.2 \mathrm{eV}$ (pyridinic $\mathrm{N}$ ), respectively in $\mathrm{N} 1 s$ spectra and one peak at $287.6 \mathrm{eV}$ assigned to triazine ring in $\mathrm{C} 1 s$ spectra. ${ }^{[45,46]}$ The absence of C-O peak suggests the resin is crosslinked via methylene bridges rather than ether bridges. Only a single peak at $192.2 \mathrm{eV}$ corresponding to $\mathrm{B}-\mathrm{O}$ in boron oxide is displayed in $\mathrm{B} 1 s$ spectra, indicating that boron oxide is physically interacted with resin at this temperature but not yet interacting chemically. At $300{ }^{\circ} \mathrm{C}$, we 
observe the contribution of B-O-C bonds at $192 \mathrm{eV}$ in B1s spectra. ${ }^{[47,48]}$ The appearance of this new bond is supported by the new $\mathrm{C}-\mathrm{O}$ peak $(286.4 \mathrm{eV})$ in $\mathrm{C} 1 s$ spectrum, revealing that chemical interactions between boron oxide and the MF resin start at $300{ }^{\circ} \mathrm{C}$. Further increasing the temperature to $400{ }^{\circ} \mathrm{C}$ does not alter the $\mathrm{B} 1 s$ spectra. However, the main peak in $\mathrm{C} 1 s$ shifts to a higher binding energy. This observation together with the presence of graphitic N (400.3 $\mathrm{eV}$ ) in $\mathrm{N} 1 s$ spectrum suggests the evolution from triazine to heptazine likely from the melonbased structure, an intermediate commonly observed in carbon nitride, g- $\mathrm{C}_{3} \mathrm{~N}_{4}$, evolution. ${ }^{[49,50]}$ At $600{ }^{\circ} \mathrm{C}$, we observe the formation of boronoxynitride, an important intermediate in forming porous BN, as evidenced by the new peaks at $191.2 \mathrm{eV}(\mathrm{B} 1 s)$ and $399.6 \mathrm{eV}(\mathrm{N} 1 s) .{ }^{[19,44]}$ Our findings show that all the boron atoms chemically interact with the resin skeleton by either via B-O-C or B-O-N bond at $600{ }^{\circ} \mathrm{C}$. BN is subsequently formed at $800{ }^{\circ} \mathrm{C}$, as evidenced by the peaks at $190.6 \mathrm{eV}$ and $398.2 \mathrm{eV}$ from $\mathrm{B} 1 s$ and $\mathrm{N} 1 s$, respectively. The majority of carbon atoms are removed at this stage as seen in Figure $6 \mathrm{~d}$ and as suggested by the lighter color of the 800 ${ }^{\circ} \mathrm{C}$ intermediate. ${ }^{[1,52]}$ Further increasing the temperature boosts carbon and oxygen removal and $\mathrm{BN}$ conversion through nitridation, resulting in a porous $\mathrm{BN}$ with a bright yellow color. The structural evolution above is supported by the analysis from FTIR shown in Figure S11. 

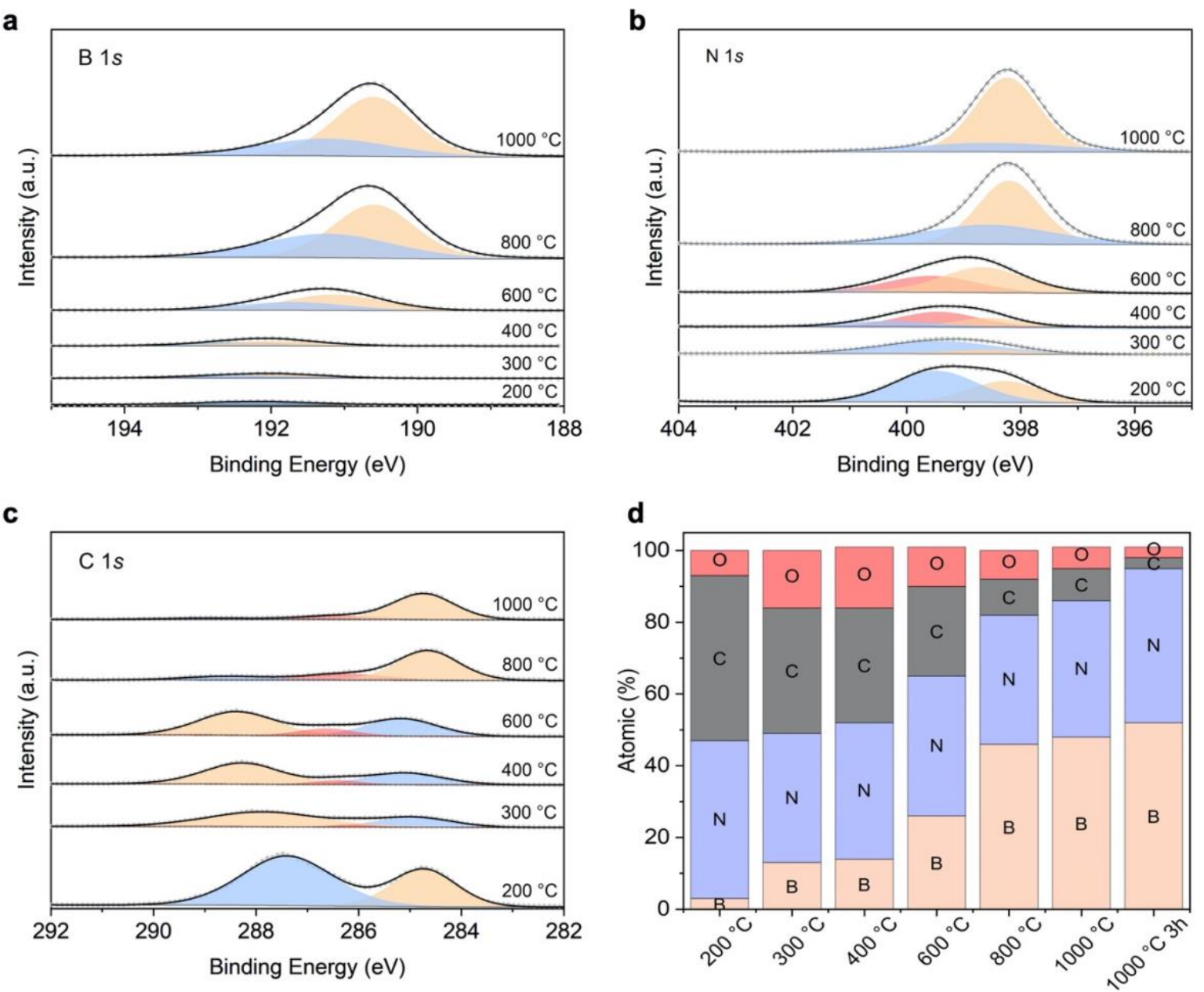

Figure 6. Surface composition of intermediates obtained at different temperatures as determined by high resolution XPS spectra: (a) B $1 s$; (b) $\mathrm{N} 1 s$; (c) $\mathrm{C} 1 s$; (d) XPS relative atomic percentage of intermediates.

Based on the analysis above, we propose the structural evolution from MF resin to $\mathrm{mp} B \mathrm{~N}$ as shown in Figure 7. First, methylene bridged MF resin bonds chemically to boron oxide via BC-O. Then, the formation of a melon-based polymer takes place. Carbon atoms are gradually removed while the remaining compounds retain the crosslinked structure via $\mathrm{B}-\mathrm{O}-\mathrm{C}$ and $\mathrm{B}-\mathrm{O}-$ $\mathrm{N}$ bonds. $\mathrm{BN}$ is then formed via a nitridation process and eventually the monolithic $\mathrm{BN}$ with minimum impurities is produced. Throughout $\mathrm{mp}_{\mathrm{BN}}$ formation, a crosslinked structure is maintained. This high bonding density in turns allows mechanical robustness to be preserved in the final product. This structural evolution study paves the way for further engineering of ${ }_{\mathrm{mp}} \mathrm{BN}$ at larger scale. 


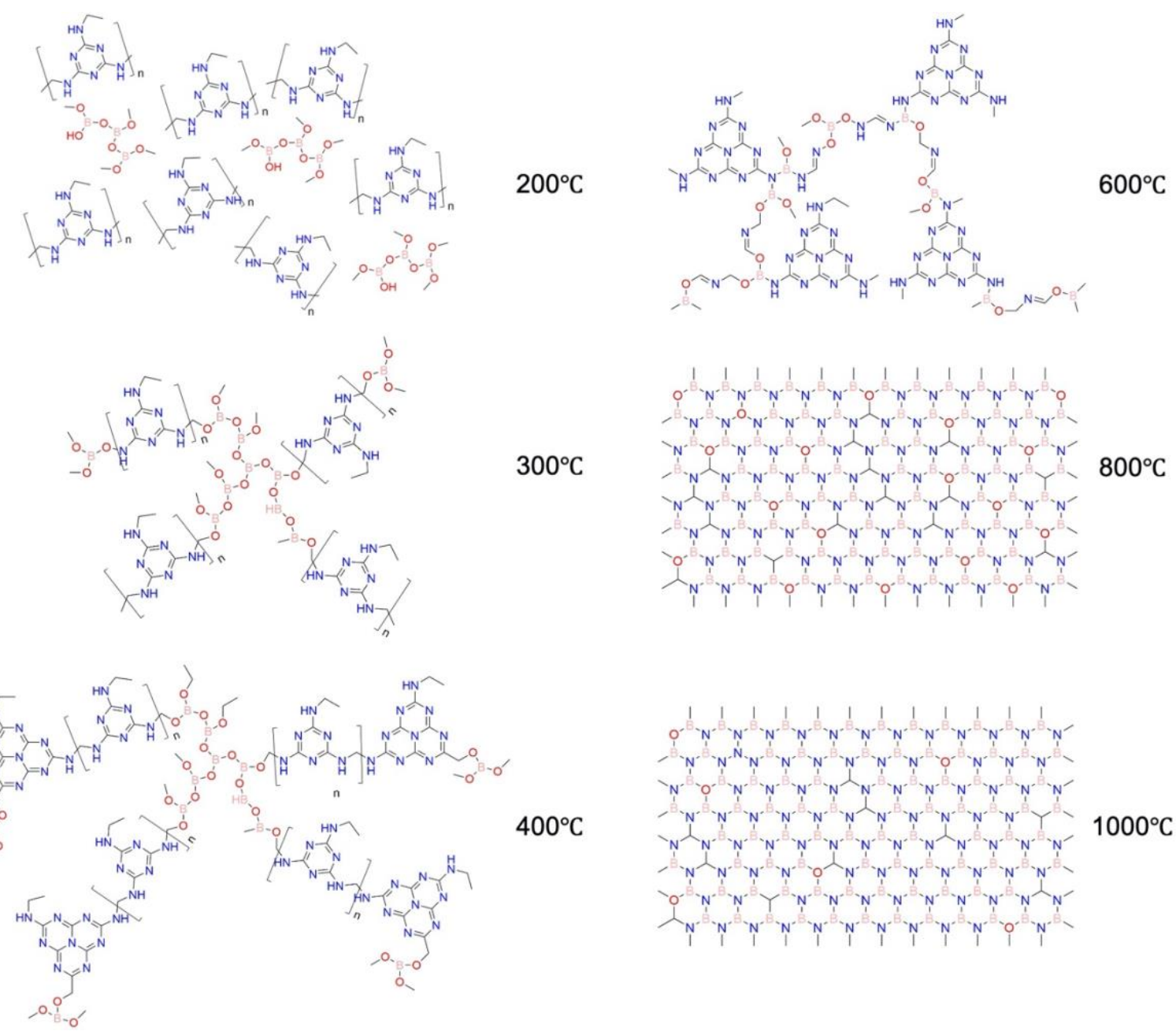

Figure 7. Proposed structural evolution of monolithic porous $\mathrm{BN}\left(\mathrm{mp}_{\mathrm{p}} \mathrm{BN}\right)$, using melamineformaldehyde resin, $\mathrm{MF}$ resin, as a precursor and $\mathrm{NH}_{3}$ as the pyrolysis atmosphere.

\section{Conclusion}

We have developed a monolithic porous $\mathrm{BN}\left({ }_{\mathrm{mp}} \mathrm{BN}\right)$ using a porous melamine-formaldehyde resin (MF resin) as precursor. A suitable range of pore density in the precursor and a $\mathrm{NH}_{3}$ synthesis atmosphere are necessary to obtain porous ${ }_{\mathrm{mp}} \mathrm{BN}$. Compared to $\mathrm{BN}$ powders, $\mathrm{mp} \mathrm{BN}$ exhibits an improved hydrolytic stability, a 50\% higher bulk density and therefore an increased volumetric surface area, the highest among $\mathrm{BN}$ materials reported to date. As a result, ${ }_{\mathrm{mp}} \mathrm{BN}$ displays an enhanced volumetric $\mathrm{CH}_{4}$ adsorption capacity, while sorption kinetics remains fast. ${ }_{\mathrm{mp}} \mathrm{BN}$ shows remarkable mechanical strength (i.e. hardness), being one to two orders of magnitude higher than that of aerogels. Studying the ${ }_{\mathrm{mp}} \mathrm{BN}$ formation mechanism, we found that the polymer intermediates derived from the resin crosslink with boron atoms, which impart 
the mechanical stability to $\mathrm{mp}_{\mathrm{BN}}$. The promising properties support the potential of $\mathrm{mpN}_{\mathrm{B}}$ for practical molecular adsorption applications and the formation mechanism study facilitates the industrial scale production of $\mathrm{mp}_{\mathrm{BN}}$.

\section{Experimental Section}

Materials: Melamine (99\%), and boric acid ( $\geq 99.5 \%)$ were purchased from Sigma-Aldrich; dicyandiamide (99.5\%), and formaldehyde solution (37\%) were purchased from Fisher. All chemicals were used as received. The gases used in this study, namely $\mathrm{NH}_{3}(99.98 \%), \mathrm{CH}_{4}$ (99.5\%), N2 (99.9995\%), and Ar (99.999\%) were purchased from BOC.

Synthesis of monolithic porous $B N\left({ }_{m p} B N\right)$ : A mechanically robust melamine-formaldehyde resin, referred to as MF resin, was used as the precursor to synthezise monolithic porous BN. The overall synthesis procedure is shown in Scheme 1 and described below. To synthezise the MOF resin, formaldehyde $(5 \mathrm{~mL}), \mathrm{NaOH}(1 \mathrm{~m}, 0.15 \mathrm{~mL})$ and melamine $(2.08 \mathrm{~g})$ were mixed in a $50 \mathrm{~mL}$ round bottom flask and stirred at $90{ }^{\circ} \mathrm{C}$ for $1 \mathrm{~h}$. Dicyandiamide $(1.5 \mathrm{~g})$ was then added to the transparent solution and stirred for $5 \mathrm{~min}$. Boric acid $(1 \mathrm{~g})$ was added to the transparent solution and vigorously stirred for $2 \mathrm{~min}$, followed by a curing step at $80{ }^{\circ} \mathrm{C}$ overnight. The collected transparent solid was further dried at $120{ }^{\circ} \mathrm{C}$ under vacuum overnight and is referred to as MF resin. The MF resin 'slab' broke into small pieces after vacuum treatment. The MF resin was placed in an alumina boat crucible and transferred to a tubular furnace. The resin was first degassed at room temperature under Ar flow $\left(250 \mathrm{~mL} \mathrm{~min}{ }^{-1}\right)$. Upon completion of the degassing, the sample was heated to $1000{ }^{\circ} \mathrm{C}\left(10{ }^{\circ} \mathrm{C} \mathrm{min}^{-1}\right)$ under pure $\mathrm{NH}_{3}$ gas flow $(100 \mathrm{~mL}$ $\min ^{-1}$ ) and held isothermally for $3 \mathrm{~h}$, unless otherwise specified. The furnace was cooled naturally under $\mathrm{NH}_{3}$ to $600{ }^{\circ} \mathrm{C}$ and then to room temperature under Ar. Light yellow monoliths were collected after the synthesis and further dried at $120^{\circ} \mathrm{C}$ under vacuum overnight.

Material characterization: Infrared (IR) spectra were collected using a PerkinElmer Spectrum 100 spectrometer equipped with an attenuated total reflectance accessory. The 
samples were first ground using an agate mortar and spectra were collected in the range of 650 $-4000 \mathrm{~cm}^{-1}$. X-ray photoelectron spectroscopy (XPS) was performed on a Thermo Scientific K-Alpha ${ }^{+}$X-ray photoelectron spectrometer equipped with a MXR3 Al K $\alpha$ monochromated Xray source $(\mathrm{h} v=1486.6 \mathrm{eV})$. The samples were initially ground and mounted onto an XPS sample holder using a small piece of conductive carbon tape. The X-ray gun power was set to $72 \mathrm{~W}(6 \mathrm{~mA}$ and $12 \mathrm{kV})$. The high-resolution spectra were obtained using $20 \mathrm{eV}$ pass energy and $0.1 \mathrm{eV}$ step size. Thermo Avantage software was used to analyze the data. Powder X-ray diffraction (PXRD) patterns were recorded using a PANalytical X'Pert PRO diffractometer using $\mathrm{Cu} \mathrm{K} \alpha$ radiation $\left(\lambda=1.54178 \AA\right.$ ) with a step of $0.01^{\circ}$ at a scanning speed of 10 s per step. An anode voltage of $40 \mathrm{kV}$ and emission current of $20 \mathrm{~mA}$ were chosen as the operating conditions. Scanning electron microscope (SEM) images were taken using a Zeiss Auriga microscope with an accelerating voltage of $5 \mathrm{kV}$. The samples were placed on the carbon tape without grinding and coated with $15 \mathrm{~nm}$ of gold. $\mathrm{N}_{2}$ adsorption isotherms were undertaken at $77 \mathrm{~K}$, using a Micromeritics 3Flex instrument. The samples were initially degassed overnight at $120^{\circ} \mathrm{C}$ at approximately 0.2 mbar pressure. Prior to the sorption isotherm measurement, the samples were further degassed in-situ for $4 \mathrm{~h}$ at $120{ }^{\circ} \mathrm{C}$. The equivalent specific surface areas of the samples were determined using the Brunauer-Emmett-Teller (BET) method. ${ }^{[53]}$ The total pore volume was evaluated from the volume of $\mathrm{N}_{2}$ adsorbed at a relative pressure $\left(\mathrm{P} / \mathrm{P}_{0}\right)$ of 0.97 . The micropore volume was determined using the Dubinin-Radushkevich model. ${ }^{[54]}$ The pore size distribution was derived from the built-in software from Micromeritics, using DFT model for carbon slit shape pores. Rate of adsorption data was logged by intercepting the raw 3Flex data output using PuTTy. Mercury porosimetry was employed up to a final pressure of 2300 bar using an AutoPore IV 9500 instrument from Micromeritics to measure the bulk density. Prior to the analysis, the samples were activated overnight at $120^{\circ} \mathrm{C}$ under vacuum.

Moisture stability test: A vial with $20 \mathrm{~mL}$ of DI water was placed in a $1 \mathrm{~L}$ sealed container until the relative humidity reached $>99 \%$, which was measured by a hygrometer. mpBN was 
kept in the container for different durations before it was collected and dried at $120{ }^{\circ} \mathrm{C}$ under vacuum.

Mechanical stability test: The hardness of ${ }_{\mathrm{mp}} \mathrm{BN}$ was measured using a Struers Duramin -1/2 Micro-Vickers hardness tester, following the Vickers method. A load of $0.025 \mathrm{kgf}$ ( $1 \mathrm{kgf}=$ $9.8 \mathrm{~N}$ ) was applied with a dwell time of $12 \mathrm{~s}$. For each sample, at least 10 indentations were performed at different points. The samples were polished on 2000 grit sandpaper with a Struers TegraPol-31 polisher before the measurement.

Methane adsorption isotherms: High-pressure $\mathrm{CH}_{4}$ adsorption isotherms were carried out at $298 \mathrm{~K}$ in the pressure range of $0-70$ bar using the equipment and method reported before. ${ }^{[55]} \mathrm{In}$ brief, $\mathrm{CH}_{4}$ uptake was measured gravimetrically using a Rubotherm Magnetic Suspension Balance (MSB) with an equilibration time of at least 90 min for each pressure point. The samples were initially degassed in a vacuum oven overnight at $393 \mathrm{~K}$ and approximately 0.2 mbar pressure. Prior to the sorption isotherm measurement, the samples were further degassed in-situ for $12 \mathrm{~h}$ at $393 \mathrm{~K}$ and a Helium gravimetry experiment was carried out at $298 \mathrm{~K}$ to estimate the adsorbent skeletal density.

\section{Supporting Information}

Supporting Information is available below.

\section{Acknowledgements}

The authors would like to thank Dr Les Bolton for his technical input, Professor Jin-Chong Tan for his kind advices for mechanical stability tests and Professor Stephen Skinner for providing the lab space to conduct the synthesis. The authors would also like to acknowledge the funding and technical support from BP through the BP International Centre for Advanced Materials (BP-ICAM), which made this research possible as well as EPSRC for the funding through the CDT in Advanced Characterization of Materials (CDT-ACM) (EP/S515085/1) and the Impact Acceleration Account scheme (EP/R511547/1). DD and CP are grateful to the EPSRC for providing funding to undertake this research via the UK Carbon Capture and Storage Research Centre (UKCCSRC, grant EP/P026214/1). JH acknowledges the funding support from the Australian Research Council (DE190100803) and the University of Queensland (UQECR2057677).

\section{Conflict of Interest}

The authors declare no conflict of interest. 
Received: ((will be filled in by the editorial staff))

Revised: ((will be filled in by the editorial staff)) Published online: ((will be filled in by the editorial staff))

\section{References}

[1] B. M. Weckhuysen, J. Yu, Chem. Soc. Rev. 2015, 44, 7022.

[2] M. R. Benzigar, S. N. Talapaneni, S. Joseph, K. Ramadass, G. Singh, J. Scaranto, U. Ravon, K. Al-Bahily, A. Vinu, Chem. Soc. Rev. 2018, 47, 2680.

[3] H. C. J. Zhou, S. Kitagawa, Chem. Soc. Rev. 2014, 43, 5415.

[4] M. I. Nandasiri, S. R. Jambovane, B. P. McGrail, H. T. Schaef, S. K. Nune, Coord. Chem. Rev. 2016, 311, 38.

[5] A. Feinle, M. S. Elsaesser, N. Hüsing, Chem. Soc. Rev. 2016, 45, 3377.

[6] Y. Peng, V. Krungleviciute, I. Eryazici, J. T. Hupp, O. K. Farha, T. Yildirim, J. Am. Chem. Soc. 2013, 135, 11887.

[7] J. Hou, A. F. Sapnik, T. D. Bennett, Chem. Sci. 2020, 11, 310.

[8] T. Tian, J. Velazquez-Garcia, T. D. Bennett, D. Fairen-Jimenez, J. Mater. Chem. A 2015, 3, 2999.

[9] T. Tian, Z. Zeng, D. Vulpe, M. E. Casco, G. Divitini, P. A. Midgley, J. SilvestreAlbero, J. C. Tan, P. Z. Moghadam, D. Fairen-Jimenez, Nat. Mater. 2018, 17, 174.

[10] E. C. Hammel, O. L. R. Ighodaro, O. I. Okoli, Ceram. Int. 2014, 40, 15351.

[11] P. Dibandjo, F. Chassagneux, L. Bois, C. Sigala, P. Miele, J. Mater. Chem. 2005, 15, 1917.

[12] S. Schlienger, J. Alauzun, F. Michaux, L. Vidal, J. Parmentier, C. Gervais, F. 
Babonneau, S. Bernard, P. Miele, J. B. Parra, Chem. Mater. 2012, 24, 88.

[13] Q. Weng, X. Wang, Y. Bando, D. Golberg, Adv. Energy Mater. 2014, 4, 1.

[14] J. Li, X. Xiao, X. Xu, J. Lin, Y. Huang, Y. Xue, P. Jin, J. Zou, C. Tang, Sci. Rep. 2013, 3,1 .

[15] S. Marchesini, A. Regoutz, D. Payne, C. Petit, Microporous Mesoporous Mater. 2017, $243,154$.

[16] J. Dai, X. Wu, J. Yang, X. C. Zeng, J. Phys. Chem. Lett. 2014, 5, 393.

[17] Q. Weng, X. Wang, C. Zhi, Y. Bando, D. Golberg, ACS Nano 2013, 7, 1558.

[18] J. Ye, X. Zhu, B. Cheng, J. Yu, C. Jiang, Environ. Sci. Technol. Lett. 2017, 4, 20.

[19] S. Marchesini, X. Wang, C. Petit, Front. Chem. 2019, 7.

[20] S. Marchesini, C. M. McGilvery, J. Bailey, C. Petit, ACS Nano 2017, 11, 10003.

[21] W. Lei, D. Portehault, D. Liu, S. Qin, Y. Chen, Nat. Commun. 2013, 4, 1777.

[22] F. Liu, J. Yu, X. Ji, M. Qian, ACS Appl. Mater. Interfaces 2015, 7, 1824.

[23] R. Shankar, M. Sachs, L. Francàs, D. Lubert-Perquel, G. Kerherve, A. Regoutz, C. Petit, J. Mater. Chem. A 2019, 7, 23931.

[24] Q. Weng, B. Wang, X. Wang, N. Hanagata, X. Li, D. Liu, X. Wang, X. Jiang, Y. Bando, D. Golberg, ACS Nano 2014, 8, 6123.

[25] J. Lin, X. Yuan, G. Li, Y. Huang, W. Wang, X. He, C. Yu, Y. Fang, Z. Liu, C. Tang, ACS Appl. Mater. Interfaces 2017, 9, 44732.

[26] G. Li, M. Zhu, W. Gong, R. Du, A. Eychmüller, T. Li, W. Lv, X. Zhang, Adv. Funct. Mater. 2019, 29, 1. 
[27] M. Rousseas, A. P. Goldstein, W. Mickelson, M. A. Worsley, L. Woo, A. Zettl, ACS Nano 2013, 7, 8540.

[28] Y. Song, B. Li, S. Yang, G. Ding, C. Zhang, X. Xie, Sci. Rep. 2015, 5, 1.

[29] X. Xu, Q. Zhang, M. Hao, Y. Hu, Z. Lin, L. Peng, T. Wang, X. Ren, C. Wang, Z. Zhao, C. Wan, H. Fei, L. Wang, J. Zhu, H. Sun, W. Chen, T. Du, B. Deng, G. J. Cheng, I. Shakir, C. Dames, T. S. Fisher, X. Zhang, H. Li, Y. Huang, X. Duan, Science (80-. ). 2019, 363, 723.

[30] Y. Xue, P. Dai, X. Jiang, X. Wang, C. Zhang, D. Tang, Q. Weng, X. Wang, A. Pakdel, C. Tang, Y. Bando, D. Golberg, J. Mater. Chem. A 2015, 4, 1469.

[31] S. Bernard, P. Miele, New J. Chem. 2014, 38, 1923.

[32] N. H. Ray, B. C. Lane, B. Shaw, US Patent 3931064, 1976.

[33] R. Shankar, S. Marchesini, C. Petit, J. Phys. Chem. C 2019, 123, 4282.

[34] M. Thommes, K. Kaneko, A. V. Neimark, J. P. Olivier, F. Rodriguez-Reinoso, J. Rouquerol, K. S. W. Sing, Pure Appl. Chem. 2015, 87, 1051.

[35] H. Giesche, In Handbook of Porous Solids, Wiley-VCH Verlag GmbH, Weinheim, Germany, 2008, pp. 309-351.

[36] J. G. Alauzun, S. Ungureanu, N. Brun, S. Bernard, P. Miele, R. Backov, C. Sanchez, J. Mater. Chem. 2011, 21, 14025.

[37] X. Zeng, L. Ye, S. Yu, R. Sun, J. Xu, C. P. Wong, Chem. Mater. 2015, 27, 5849.

[38] Y. Joo Jeong, M. F. Islam, Nanoscale 2015, 7, 12888.

[39] M. Wang, T. Zhang, D. Mao, Y. Yao, X. Zeng, L. Ren, Q. Cai, S. Mateti, L. H. Li, X. 
Zeng, G. Du, R. Sun, Y. Chen, J. Bin Xu, C. P. Wong, ACS Nano 2019, 13, 7402.

[40] W. Lei, V. N. Mochalin, D. Liu, S. Qin, Y. Gogotsi, Y. Chen, Nat. Commun. 2015, 6, 1.

[41] C. N. Yeh, H. Huang, A. T. O. Lim, R. H. Jhang, C. H. Chen, J. Huang, Nat. Commun. 2019, 10 .

[42] J. H. Pikul, S. Özerinç, B. Liu, R. Zhang, P. V. Braun, V. S. Deshpande, W. P. King, Sci. Rep. 2019, 9, 1.

[43] H. Kashani, Y. Ito, J. Han, P. Liu, M. Chen, Sci. Adv. 2019, 5, 1.

[44] T. Woignier, J. Primera, A. Alaoui, F. Despetis, S. Calas-Etienne, A. Faivre, L. Duffours, C. Levelut, P. Etienne, J. Sol-Gel Sci. Technol. 2020, 93, 6.

[45] S. Zhuang, E. S. Lee, L. Lei, B. B. Nunna, L. Kuang, W. Zhang, Int. J. Energy Res. 2016, 40, 2136.

[46] A. Deryło-Marczewska, J. Goworek, S. Pikus, E. Kobylas, W. Zgrajka, Langmuir 2002, 18,7538 .

[47] J. Jana, M. Ganguly, K. R. S. Chandrakumar, G. M. Rao, T. Pal, Langmuir 2017, 33, 573.

[48] H. Fang, C. Yu, T. Ma, J. Qiu, Chem. Commun. 2014, 50, 3328.

[49] S. Dyjak, W. Kiciński, A. Huczko, J. Mater. Chem. A 2015, 3, 9621.

[50] T. S. Miller, A. B. Jorge, T. M. Suter, A. Sella, F. Corà, P. F. McMillan, Phys. Chem. Chem. Phys. 2017, 19, 15613.

[51] Y. Gong, G. Shi, Z. Zhang, W. Zhou, J. Jung, W. Gao, L. Ma, Y. Yang, S. Yang, G. 
You, R. Vajtai, Q. Xu, A. H. Macdonald, B. I. Yakobson, J. Lou, Z. Liu, P. M. Ajayan, Nat. Commun. 2014, 5.

[52] C. Wu, B. Wang, N. Wu, C. Han, X. Zhang, S. Shen, Q. Tian, C. Qin, P. Li, Y. Wang, Ceram. Int. 2020, 46, 1083.

[53] S. Brunauer, P. H. Emmett, E. Teller, J. Am. Chem. Soc. 1938, 60, 309.

[54] S. G. Chen, R. T. Yang, Langmuir 1994, 10, 4244.

[55] H. Ansari, L. Joss, J. Hwang, J. P. M. Trusler, G. Maitland, R. Pini, Microporous Mesoporous Mater. 2020, 308, 110537. 


\section{Supporting Information}

Mechanically stable monolithic porous boron nitride with high volumetric adsorption capacity

Tian Tian, Jingwei Hou, Humera Ansari, Ying Xiong, Anouk L'Hermitte, David Danaci, Ronny Pini, and Camille Petit*

1. Synthesis of monolithic porous $(\mathrm{mp} B N)$

\subsection{Effects of dicyandiamide (DCD)}
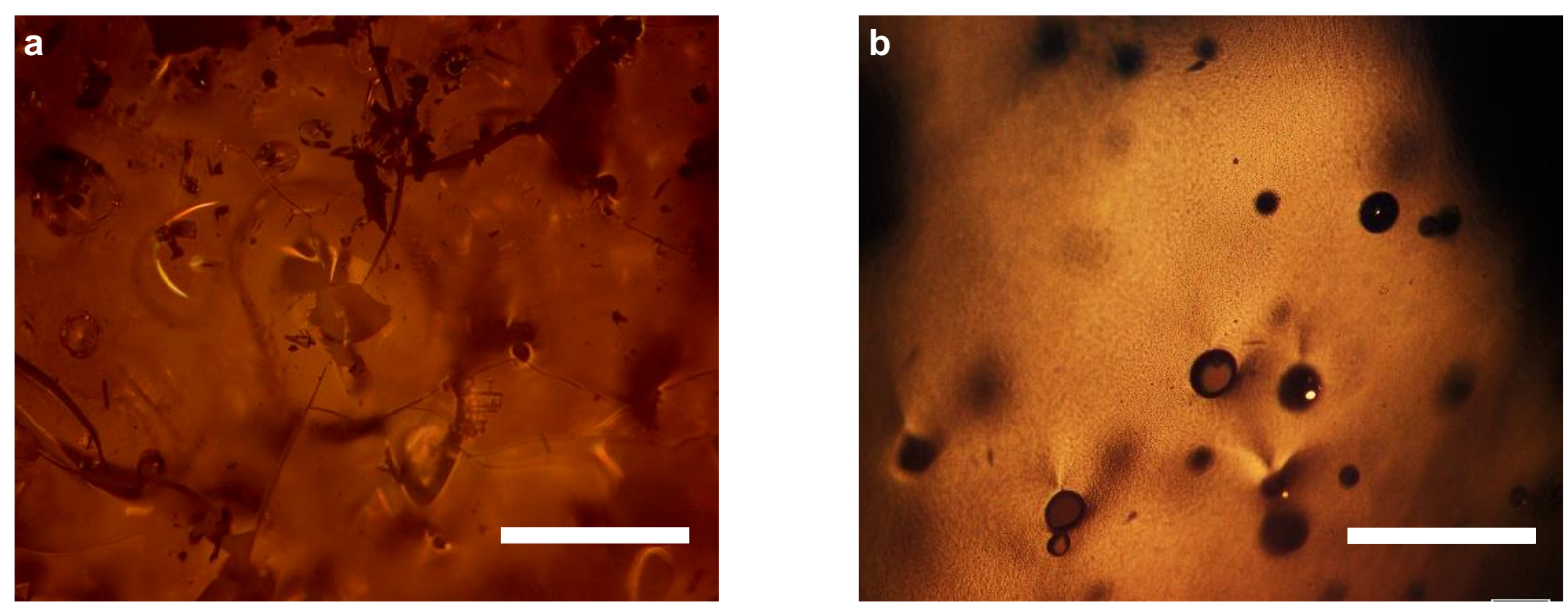

Figure S1. Microscope images of MF resin with (a) $0.5 \mathrm{~g}$ DCD and (b) $1.5 \mathrm{~g}$ DCD. Scale bar $=100 \mu \mathrm{m}$. 


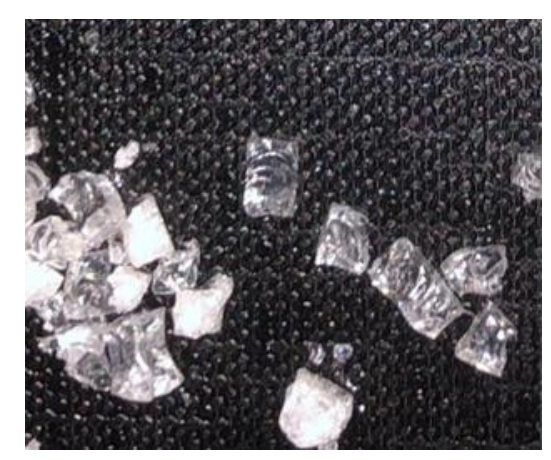

Figure S2. Optical image of MF resin with $1.5 \mathrm{~g}$ DCD before the transparent samples were collected. 


\subsection{Effects of reaction gas on $\mathrm{mp} B N$}
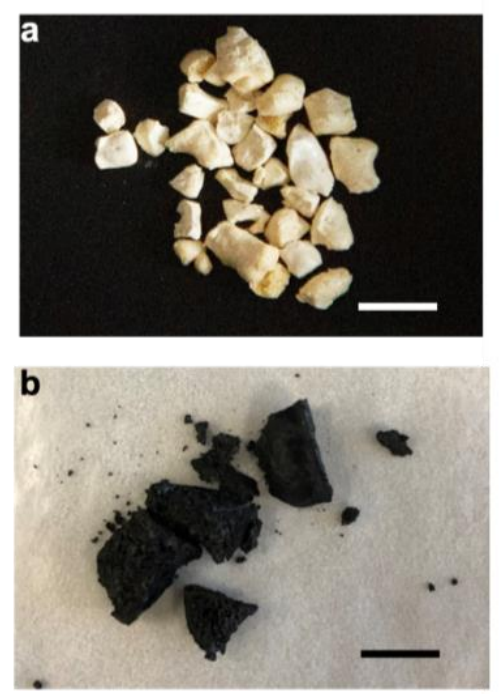

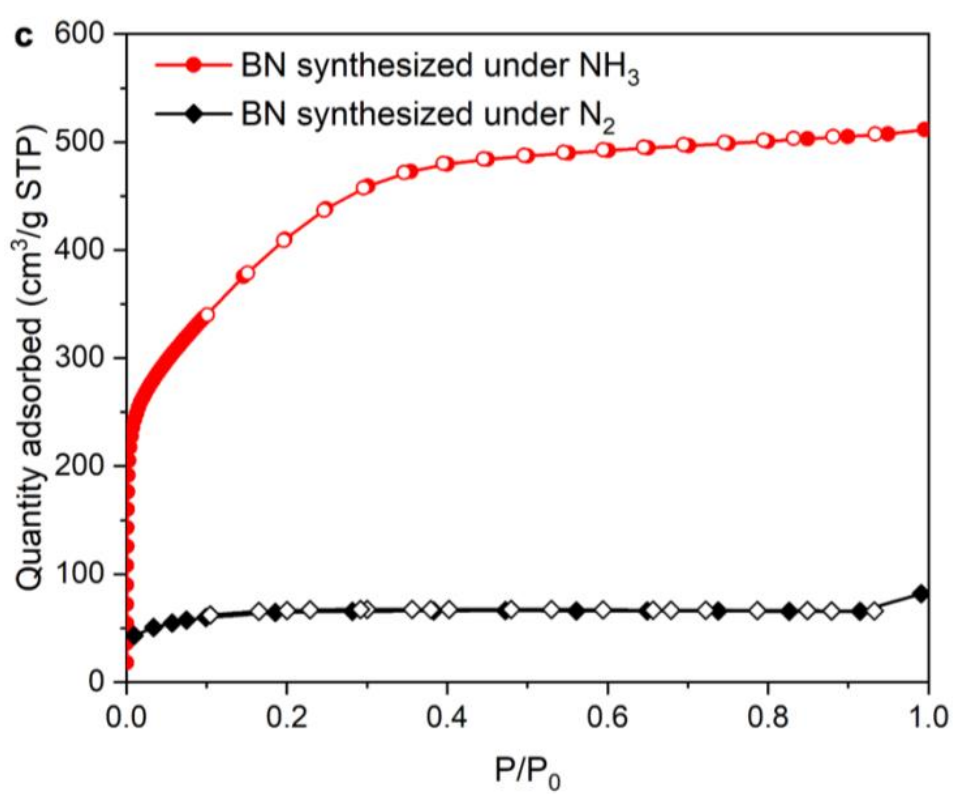

Figure S3. Optical images of porous $\mathrm{BN}$ obtained under (a) $\mathrm{NH}_{3}$ and (b) $\mathrm{N}_{2}$. Scale bar $=1 \mathrm{~cm}$. c) $\mathrm{N}_{2}$ sorption isotherms at $77 \mathrm{~K}$ for $\mathrm{BN}$ synthesized under $\mathrm{NH}_{3}$ (red circles) and $\mathrm{N}_{2}$ (black diamonds). 


\section{Moisture stability of monolithic $B N\left({ }_{m p B N}\right)$ and powder $B N$}

The hydrolytic instability of porous $\mathrm{BN}$ has been highlighted in previous studies and represents a major barrier to industrial applications. ${ }^{[1,2]}$ Figures S4 and S5 show the influence of moisture (> 99\% humidity) exposure time on the BET area of ${ }_{\mathrm{mpN}} \mathrm{BN}$ and powder BN. Both samples show virtually the same BET areas after the first hour. However, the porosity decreased significantly after $2 \mathrm{~h}$ of exposure for powder BN, showing a 54\% loss in the surface area. For ${ }_{\mathrm{mpN}} \mathrm{BN}$, the reduction was of $18 \%$. More importantly, $\mathrm{mp}_{\mathrm{BN}}$ maintains more than $60 \%$ of its original surface area after $8 \mathrm{~h}$ exposure, whereas powder BN only retains $15 \%$. A $25 \%$ more drop of the surface area is observed for ${ }_{\mathrm{mp}} \mathrm{BN}$ after further $4 \mathrm{~h}$ exposure, at which point powder BN is virtually non-porous.

We analyzed structural changes in both samples upon exposure to moisture using XRD. In the case of powder BN (Figure S4b), the (002) peak related to hexagonal BN increases in intensity and shifts to higher angles after exposure to moisture. This observation agrees with previous studies and indicates a loss of the amorphous portion of $\mathrm{BN}$ upon decomposition in water, leaving the residual material with a higher crystallinity (i.e. lower porosity and surface area). ${ }^{[3]} \mathrm{mp}_{\mathrm{BN}}$ exhibits a different trend (Figure $\mathrm{S} 4 \mathrm{c}$ ). The sample does not show any increase in crystallinity before $12 \mathrm{~h}$ of exposure. This observation suggests a slower degradation compared to powder BN, consistent with the BET area trend (Figure S5a). We attribute the greater hydrolytic stability of ${ }_{\mathrm{mp}} \mathrm{BN}$ compared to that of powder $\mathrm{BN}$ to its lower content of oxygen atom (3 at\% vs 9 at\%). Indeed, oxygen sites are susceptible to hydrolysis attack as observed in other studies. ${ }^{[2]}$ 

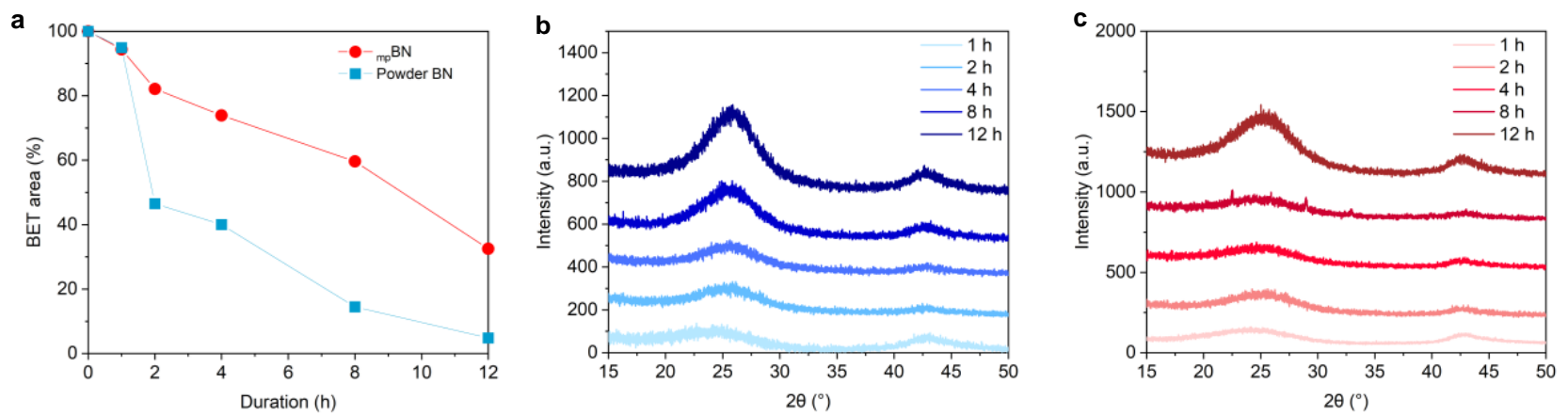

Figure S4. Structural features of monolithic porous $\mathrm{BN}(\mathrm{mp} B N)$ and powder $\mathrm{BN}$ after moisture exposure. (a) BET surface area loss as derived from $\mathrm{N}_{2}$ sorption at $77 \mathrm{~K}$; (b) XRD patterns of powder BN; (c) XRD patterns of ${ }_{m p} B N$. 

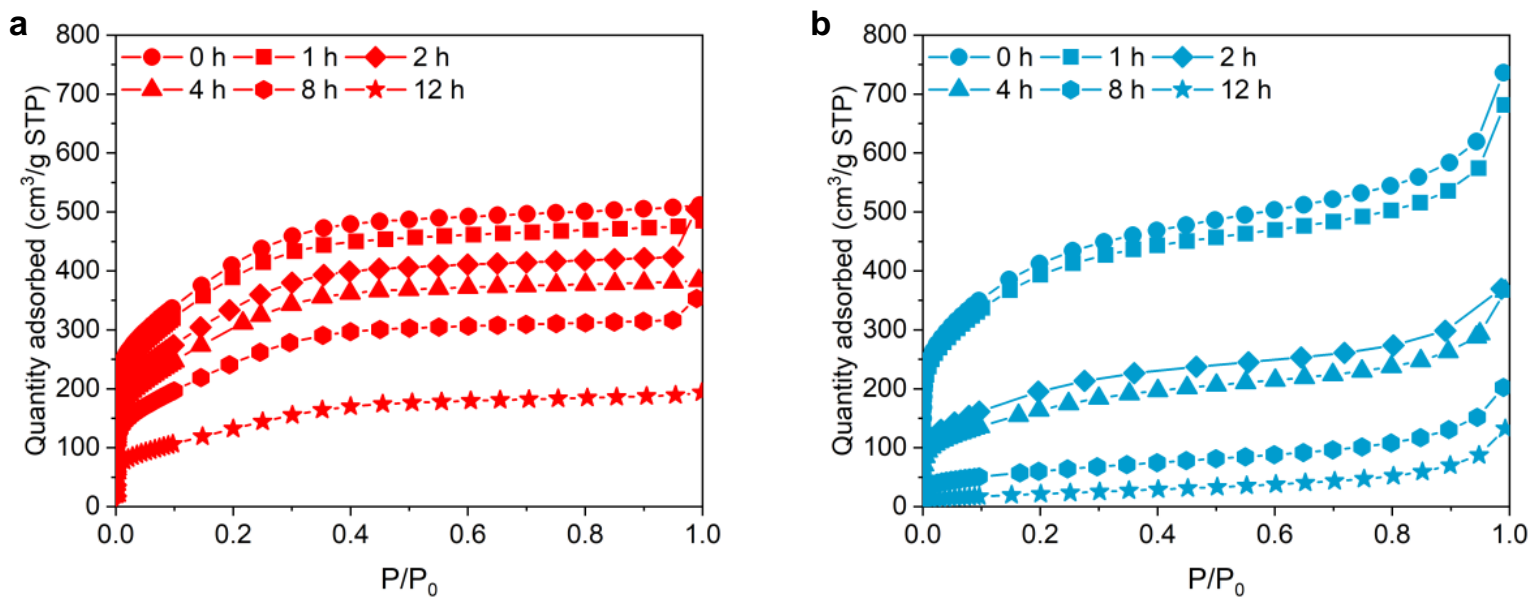

Figure S5. $\mathrm{N}_{2}$ adsorption isotherms at $77 \mathrm{~K}$ after moisture exposure: (a) structured $\mathrm{BN}$; (b) powder BN; 0 h, circle; 1 h, square; $2 \mathrm{~h}$, diamond; $4 \mathrm{~h}$, triangle; $8 \mathrm{~h}$, hexagon; $12 \mathrm{~h}$, star. 
3. Gas adsorption: monolithic porous $\mathrm{BN}(\mathrm{mp} B \mathrm{~N})$ vs powder BN

\section{1. $\mathrm{N}_{2}$ adsorption isotherms at $77 \mathrm{~K}$.}
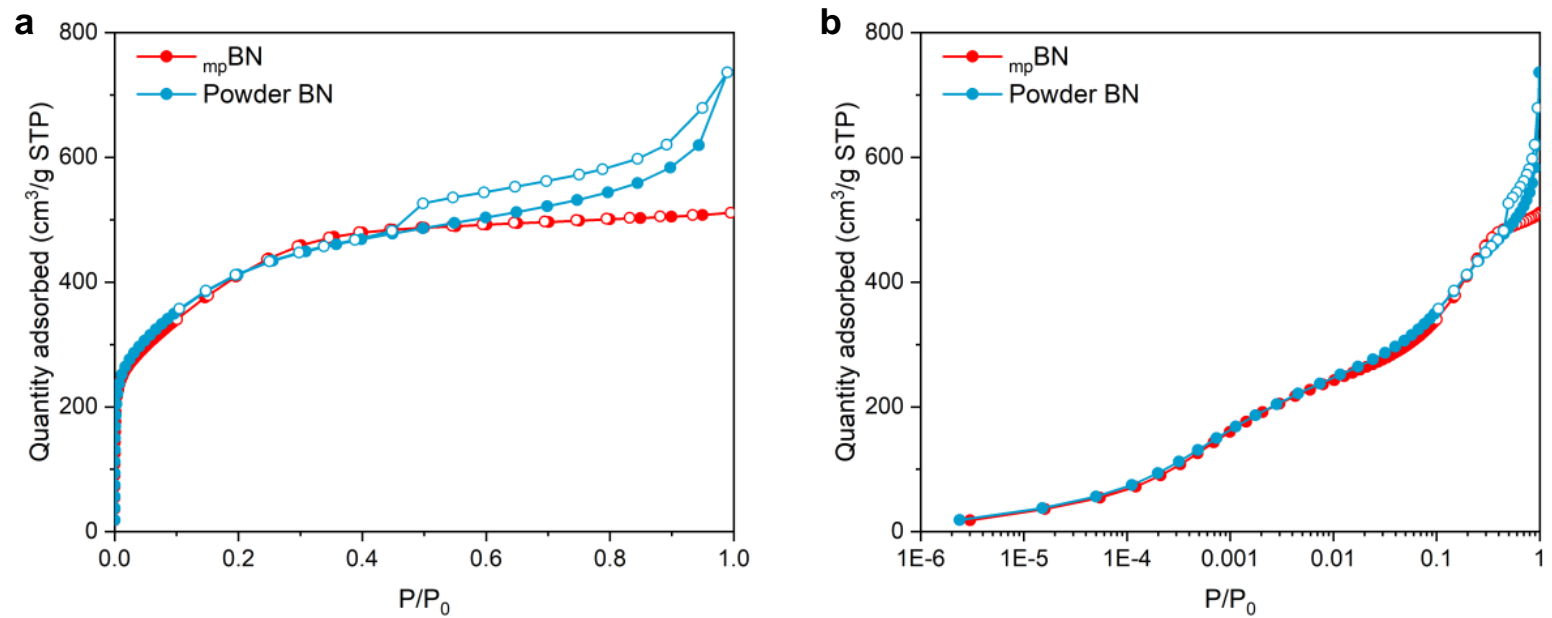

Figure S6. $\mathrm{N}_{2}$ adsorption isotherms at $77 \mathrm{~K}$ for $\mathrm{mpN}_{\mathrm{BN}}$ and powder $\mathrm{BN}$ in a) linear scale; $\mathrm{b}$ ) semi-logarithmic scale. 


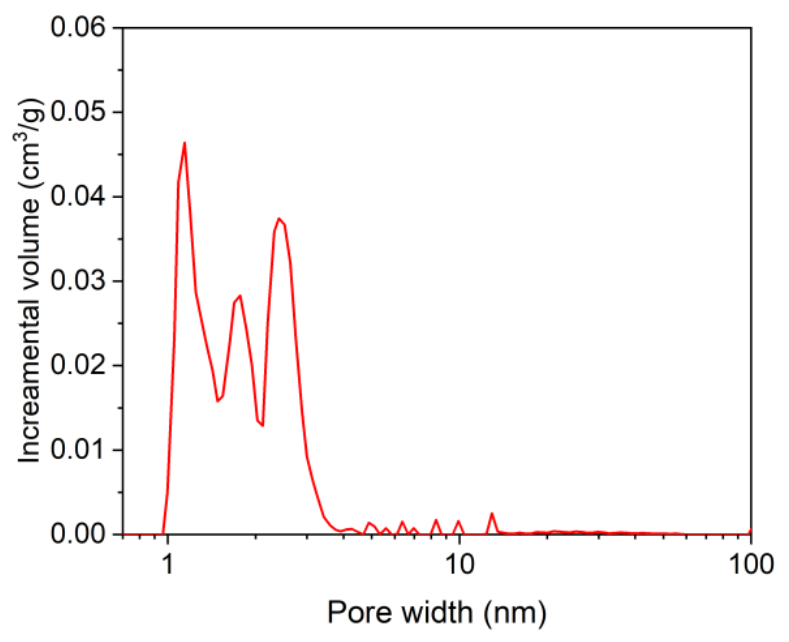

Figure S7. Pore size distribution of ${ }_{\mathrm{mp}} \mathrm{BN}$ as derived from $\mathrm{N}_{2}$ adsorption isotherms at $77 \mathrm{~K}$. 


\subsection{Bulk density measurement via mercury porosimetry.}

We measured the bulk density of both ${ }_{\mathrm{mp}} \mathrm{BN}$ and powder $\mathrm{BN}$ using mercury porosimetry, a well-established technique that has been used to measure the bulk density of other porous materials. Mercury is a non-wetting liquid that does not intrude into small pores at ambient pressure, facilitating the measurement of bulk volume, which includes both the material volume and the interstitial volume, and thus the bulk density.

In a typical mercury intrusion porosimetry measurement, the sample is filled in a penetrometer, which has a known weight and volume. It should be noted that the sample is not mechanically compressed. After evacuation, the penetrometer is filled with mercury. The mercury will surround the sample at ambient pressure but not enter pores and voids smaller than ca. $6 \mu \mathrm{m}$. The weight of mercury is obtained by reweighing the penetrometer and by subtracting the known weights of the empty penetrometer and the sample. The volume of intruded mercury is then computed from the known mercury density $\left(13.5394 \mathrm{~g} \mathrm{~mL}^{-1}\right)$ and the bulk volume of the sample is obtained as the difference between the empty penetrometer volume and the intruded mercury volume.

As powder $\mathrm{BN}$ and $\mathrm{mp}_{\mathrm{BN}}$ has the same composition and similar surface area, the materials volume of both samples can be exactly same. However, due to the more packed structure of ${ }_{\mathrm{mp}} \mathrm{BN}$ (i.e. less interparticle volume), the ${ }_{\mathrm{mp}} \mathrm{BN}$ shows much higher bulk density compared to powder BN. 


\subsection{Methane adsorption isotherms at $298 \mathrm{~K}$.}

The data of high-pressure methane uptake was obtained as excess gravimetric adsorption capacity $\left(\mathrm{N}_{\mathrm{exc}}\right)$, and was converted into absolute gravimetric capacity $\left(\mathrm{N}_{\mathrm{abs}}\right)$ using equation 1 :

$$
N_{a b s}=N_{\text {exc }}+\rho_{\text {gas }} V_{\text {micro }}
$$

where $\rho_{\text {gas }}$ is the density of the non-adsorbed gas and $V_{\text {micro }}$ is the micropore volume of the adsorbent. The skeleton volumes $\left(0.474 \mathrm{~cm}^{3} \mathrm{~g}^{-1}\right.$ for powder $\mathrm{BN}$ and $0.476 \mathrm{~cm}^{3} \mathrm{~g}^{-1}$ for $\left.\mathrm{mp} \mathrm{BN}\right)$ obtained by helium gravimetry were used to calculate the excess adsorbed capacity. ${ }^{[4]}$

Absolute volumetric adsorption capacity is converted from the absolute gravimetric uptake by multiplying by the bulk density. Bulk density is the ratio of the mass of an uncompressed solid sample and its volume, including the volume of the solid and the interparticle space.
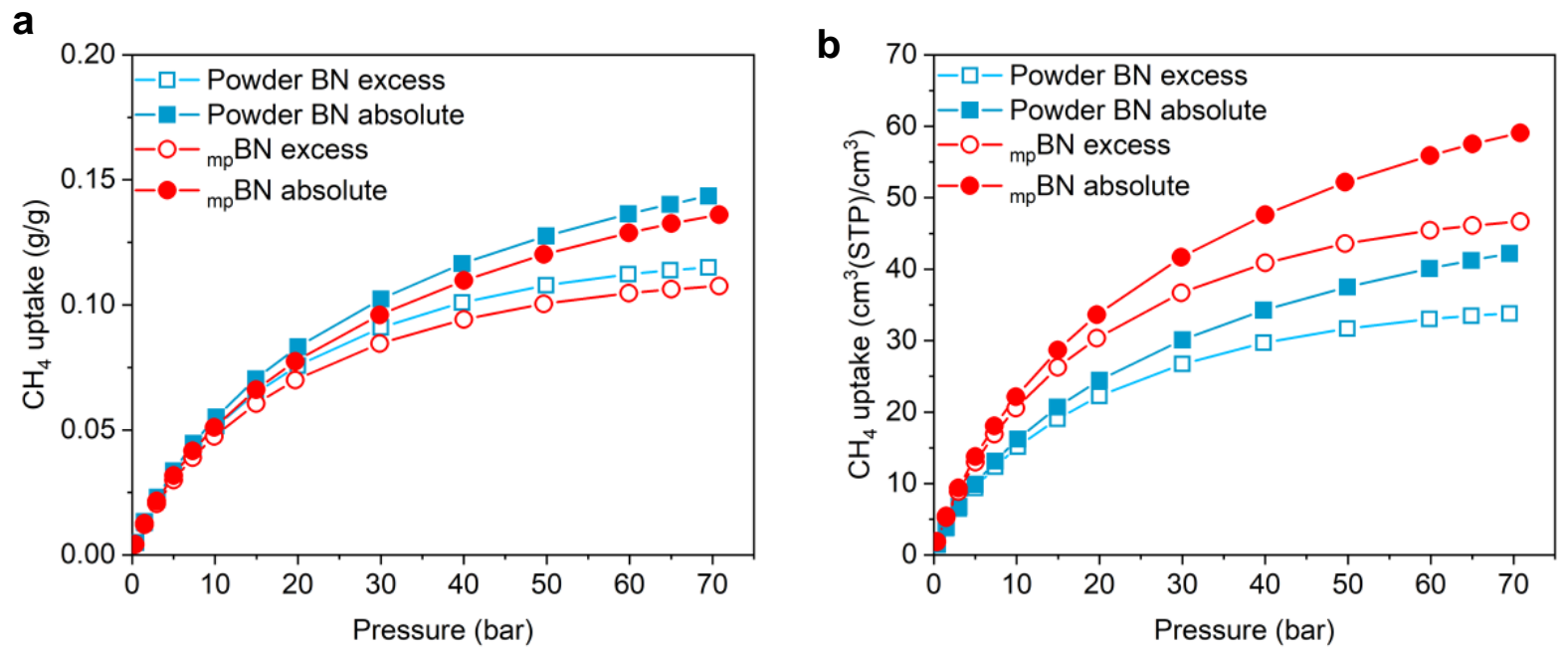

Figure S8. Comparison of absolute methane uptake at $298 \mathrm{~K}$ between powder BN (blue squares) and ${ }_{m p} \mathrm{BN}$ (red circles): a) gravimetric uptake; b) volumetric uptake. 


\section{3. $\mathrm{N}_{2}$ adsorption kinetics at $77 \mathrm{~K}$}
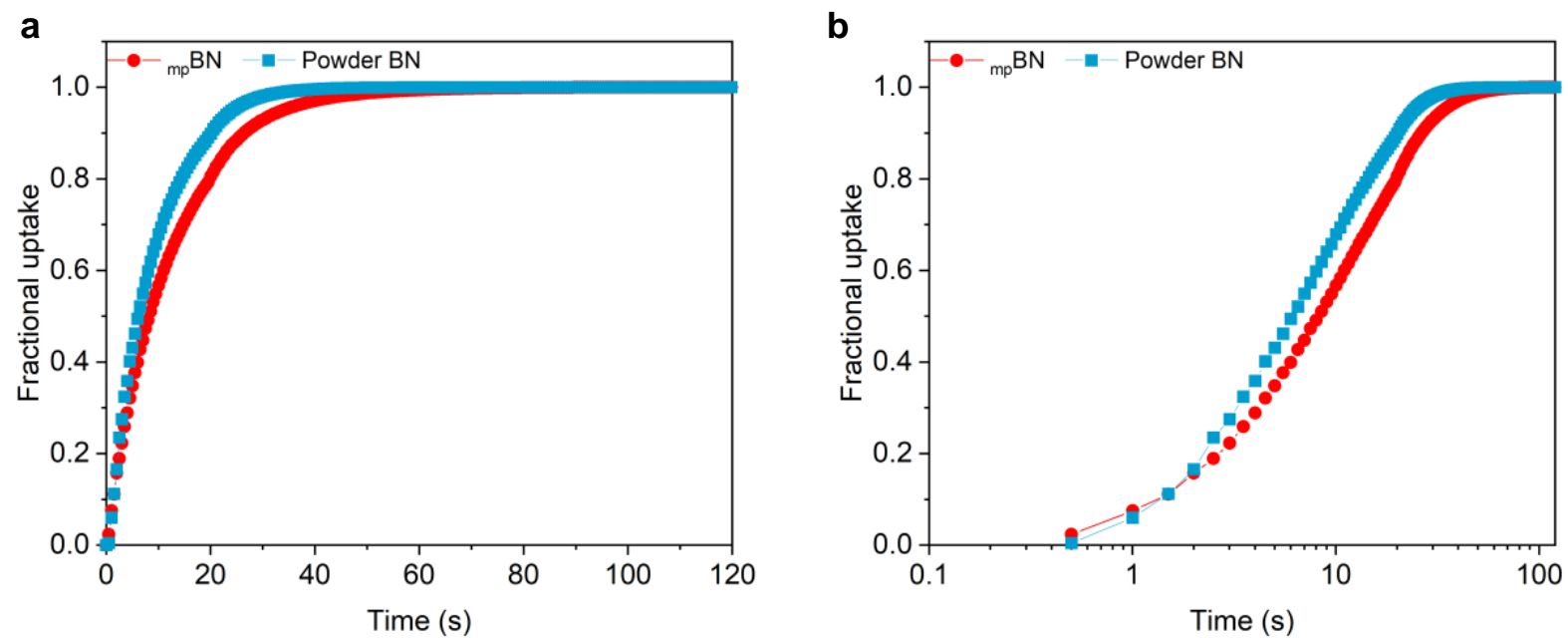

Figure S9. Comparison of adsorption kinetics of $\mathrm{N}_{2}$ uptake at $77 \mathrm{~K}$ and $2.2 \times 10^{-6}$ bar between powder BN (blue) and ${ }_{m p} \mathrm{BN}$ (red circles): (a) linear scale, (b) semi-logarithmic scale.

Fractional uptake based on Equation 2 is used to study the adsorption kinetics:

$$
\text { Fractional uptake }=\frac{m_{t}-m_{o}}{m_{e q}-m_{0}}
$$

where $m_{t}$ is the adsorption amount at time $\mathrm{t}, m_{0}$ is the adsorption amount at $\mathrm{t}=0$, and $m_{e q}$ is the adsorption amount at equilibrium. 


\section{Mechanical stability of monolithic porous $\mathrm{BN}(\mathrm{mp} B N)$}

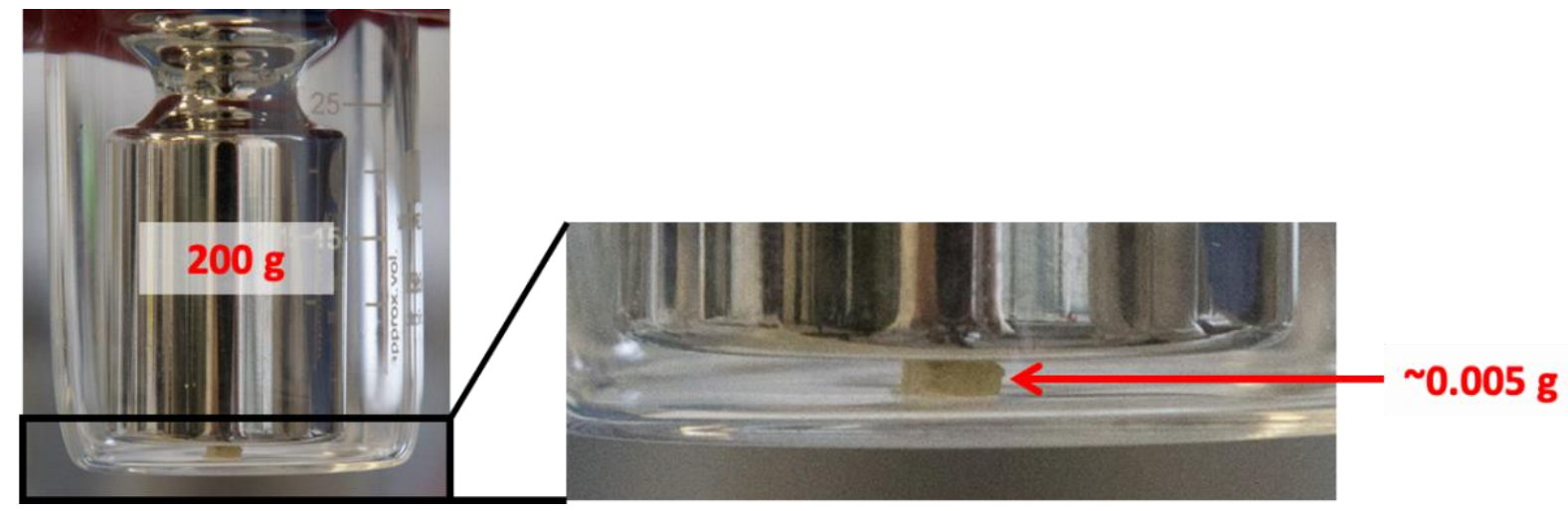

Figure S10. Optical image of structured porous BN under a $200 \mathrm{~g}$ calibration weight.

The mechanical stability is evaluated by Vickers microhardness test. To convert the Vickers hardness to SI unit (e.g. MPa), the value is multiplied by $9.807 . .^{[5]}$ 


\section{Formation mechanism}

FTIR was used to analyze the chemical composition of the intermediates. Sample collected at $200{ }^{\circ} \mathrm{C}$ shows $\mathrm{NH}_{2}$ stretching band $\left(3350 \mathrm{~cm}^{-1}\right), \mathrm{C}-\mathrm{N}$ stretching band $\left(1560,1450,1320 \mathrm{~cm}^{-1}\right)$ and a triazine ring bending band $\left(807 \mathrm{~cm}^{-1}\right) \cdot{ }^{[6]}$ All these bands indicate the successful synthesis of the MF resin. Because of the high mechanical strength of MF resin, which can be broken into small glassy pieces, together with the low content of B, the band attributed to B-containing bonds was not observed. Increasing the temperature to $300{ }^{\circ} \mathrm{C}$ leads to a new $\mathrm{C}-\mathrm{O}$ stretching band at $1320 \mathrm{~cm}^{-1}$. Both intermediates collected at 300 and $400{ }^{\circ} \mathrm{C}$ present an unknown band at around $880-890 \mathrm{~cm}^{-1}$. This band is always present in melon-based materials, indicating the existence of melon-based polymer. ${ }^{[6]}$ A new B-O stretching band $\left(1390 \mathrm{~cm}^{-1}\right)$ is observed at $400{ }^{\circ} \mathrm{C}$ due to the increased percentage of $\mathrm{B}$ in the mixture. ${ }^{[7-10]} \mathrm{A}$ very broad band between $800-1700 \mathrm{~cm}^{-1}$ at $600{ }^{\circ} \mathrm{C}$ indicates the phase transition process at this temperature. Three main characteristic bands $\left(\sim 1360,1100,790 \mathrm{~cm}^{-1}\right)$ belonging to $\mathrm{BN}$ appear when the temperature increased to $800{ }^{\circ} \mathrm{C}$ clearly suggested the formation of $\mathrm{BN}$. The IR features remained unchanged when the temperature increased to $1000{ }^{\circ} \mathrm{C}$. The FTIR analysis supports the formation mechanism hypothesis concluded from XPS analysis.

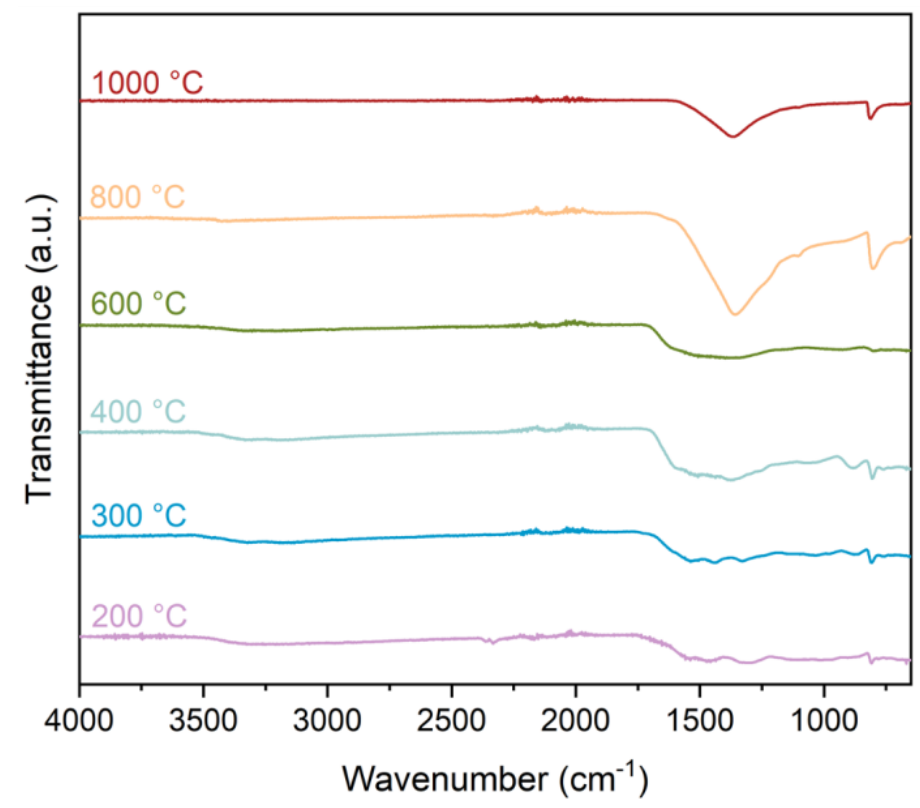

Figure S11. FTIR of intermediates obtained at different temperatures. 
References

[1] C. G. Cofer, J. Economy, Carbon N. Y. 1995, 33, 389.

[2] R. Shankar, S. Marchesini, C. Petit, J. Phys. Chem. C 2019, 123, 4282.

[3] W. Lei, V. N. Mochalin, D. Liu, S. Qin, Y. Gogotsi, Y. Chen, Nat. Commun. 2015, 6, 1.

[4] H. Ansari, L. Joss, J. Hwang, J. P. M. Trusler, G. Maitland, R. Pini, Microporous Mesoporous Mater. 2020, 308, 110537.

[5] M. M. Yovanovich, Collect. Tech. Pap. - 44th AIAA Aerosp. Sci. Meet. 2006, 16, 11702.

[6] X. Wei, Y. Qiu, W. Duan, Z. Liu, RSC Adv. 2015, 5, 26675.

[7] C. Wu, B. Wang, N. Wu, C. Han, X. Zhang, S. Shen, Q. Tian, C. Qin, P. Li, Y. Wang, Ceram. Int. 2020, 46, 1083.

[8] X. Qiao, Z. Zhou, X. Liu, C. Zhao, Q. Guan, W. Li, Catal. Sci. Technol. 2019, 9, 3753.

[9] J. Xu, Y. Li, S. Peng, G. Lu, S. Li, Phys. Chem. Chem. Phys. 2013, 15, 7657.

[10] S. J. Makowski, P. Köstler, W. Schnick, Chem. - A Eur. J. 2012, 18, 3248. 